\title{
Comparative genomics applied to Mucor species with different lifestyles
}

Annie Lebreton ${ }^{1}$, Erwan Corre², Jean-Luc Jany ${ }^{1}$, Loraine Brillet-Guéguen ${ }^{2,3}$, Carlos Pèrez-Arques ${ }^{4}$, Victoriano Garre ${ }^{4}$, Misharl Monsoor ${ }^{2}$, Robert Debuchy ${ }^{5}$, Christophe Le Meur ${ }^{1}$, Emmanuel Coton'1, Georges Barbier ${ }^{1}$ and Laurence Meslet-Cladière ${ }^{1^{*}}$ (D)

\begin{abstract}
Background: Despite a growing number of investigations on early diverging fungi, the corresponding lineages have not been as extensively characterized as Ascomycota or Basidiomycota ones. The Mucor genus, pertaining to one of these lineages is not an exception. To this date, a restricted number of Mucor annotated genomes is publicly available and mainly correspond to the reference species, Mucor circinelloides, and to medically relevant species. However, the Mucor genus is composed of a large number of ubiquitous species as well as few species that have been reported to specifically occur in certain habitats. The present study aimed to expand the range of Mucor genomes available and identify potential genomic imprints of adaptation to different environments and lifestyles in the Mucor genus.

Results: In this study, we report four newly sequenced genomes of Mucor isolates collected from non-clinical environments pertaining to species with contrasted lifestyles, namely Mucor fuscus and Mucor lanceolatus, two species used in cheese production (during ripening), Mucor racemosus, a recurrent cheese spoiler sometimes described as an opportunistic animal and human pathogen, and Mucor endophyticus, a plant endophyte. Comparison of these new genomes with those previously available for six Mucor and two Rhizopus (formerly identified as M. racemosus) isolates allowed global structural and functional description such as their TE content, core and species-specific genes and specialized genes. We proposed gene candidates involved in iron metabolism; some of these genes being known to be involved in pathogenicity; and described patterns such as a reduced number of CAZymes in the species used for cheese ripening as well as in the endophytic isolate that might be related to adaptation to different environments and lifestyles within the Mucor genus.
\end{abstract}

Conclusions: This study extended the descriptive data set for Mucor genomes, pointed out the complexity of obtaining a robust phylogeny even with multiple genes families and allowed identifying contrasting potentially lifestyle-associated gene repertoires. The obtained data will allow investigating further the link between genetic and its biological data, especially in terms of adaptation to a given habitat.

Keywords: Early divergent fungi, Genome, Adaptation, CAZymes, Peptidases, Iron uptake

\section{Background}

The Mucor genus belongs to the most prominent order of the Mucorales, a phylogenetically ancient group of fungi pertaining to the "early diverging fungi" [1]. From the first microscopic observation of a Mucor specimen in 1665 up until now, several hundreds of potential

\footnotetext{
* Correspondence: laurence.meslet@univ-brest.fr

${ }^{1}$ Univ Brest, Laboratoire Universitaire de Biodiversité et Ecologie Microbienne, F-29280 Plouzané, France

Full list of author information is available at the end of the article
}

Mucor species have been reported [2]. Mucor species are common and predominantly saprotrophs [3]. These ubiquitous microorganisms may colonize multiple and contrasted environments from dungs or dead plant materials to plant and animal tissues. Members of the Mucor genus have an ambivalent impact on human activities. Regarding their negative impact, some Mucor species, in particular the thermotolerant species Mucor indicus, Mucor ramosissimus and seven members of the Mucor circinelloides complex [4] have been shown to be

(c) The Author(s). 2020 Open Access This article is distributed under the terms of the Creative Commons Attribution 4.0 International License (http://creativecommons.org/licenses/by/4.0/), which permits unrestricted use, distribution, and reproduction in any medium, provided you give appropriate credit to the original author(s) and the source, provide a link to the Creative Commons license, and indicate if changes were made. The Creative Commons Public Domain Dedication waiver (http://creativecommons.org/publicdomain/zero/1.0/) applies to the data made available in this article, unless otherwise stated. 
human and animal pathogens responsible for mucormycosis [2]. Mucormycosis has been recently described as the third most common angioinvasive fungal infection and can lead to death [5]. Another negative impact concerns the ability of different species of the genus to spoil raw and transformed foods and feeds [6]. On the contrary, some Mucor species have an important biotechnological potential thanks to their high growth rates in a large range of temperatures [7], existence of a yeast state in certain Mucor spp. [8], and high proteolytic and lipolytic enzymatic activities [9], making them good candidates for biotechnology. Interestingly, some species are also used in food manufacturing of Asian fermented food production (such as ragi, tempeh, furu or mureha) or for French cheese ripening (such as Tomme or SaintNectaire) [2].

The increasing number of infections associated with Mucor species, as well as the biotechnological potential of the genus, have led to a large effort to better know these fungi. In this context, Vongsangnak et al. proposed a metabolic network of the oleaginous strain Mucor circicinelloides WJ11 [10, 11], Corrochano et al. shed new light on Mucor sensory perception [12], and multiple genes potentially involved in virulence were investigated and discovered in Mucor spp. [13-21]. Following the annotation of the first Mucor genome sequence (Mucor circinelloides CBS 277.49), researches on Mucor benefited and will continue to benefit from different sequencing projects including the Zygolife initiative (http://zygolife.org/home/) which aims to provide a better phylogenetical classification to the formerly called Zygomycetes which include the Mucor genus (see [1]).

This phylogenetical classification appears to be challenging as stated by inconsistencies among previous works; e.g. Mucor indicus CDC-B7402 placement was modified between the phylogeny of Álvarez et al. and that of Whalter et al., Mucor endophyticus CBS 385-95 placement was modified between Whalter et al. and Lebreton et al. respective studies [22-24]. Moreover, the uncertain taxonomic assignment of some Mucor isolates used in published studies may lead to confusion. For example, following genomic studies, the 97-1192 isolate was reassigned from Mucor racemosus to Rhizopus oryzae and isolate CDC-B9738 (initially Rhizopus microsporus) was consecutively assigned to Mucor racemosus by Chibucos et al. and more recently reassigned to $R$. microsporus by Gryganskyi et al. [13, 25]. As stated by Gryganskyi et al., the closely related genus Rhizopus cannot be deciphered with a single or even a handful of gene families [25]. However, the range of Mucor genome sequences exploited is limited and those available with annotations even scarcer. Furthermore, these genome sequencing projects are mainly limited to Mucor species with a biotechnological or pathogenic potential. Indeed, at the beginning of this study, only six Mucor annotated genomes were freely available, five of them corresponding to isolates pertaining to the $M$. circinelloides complex.

The present study aimed to use comparative genomics to identify potential genomic imprints of adaptation to different environments and lifestyles in the Mucor genus. To do so, four genomes, corresponding to Mucor fuscus UBOCC-A-109160 and Mucor lanceolatus UBOCC-A109153 (used in cheese production, during ripening), Mucor racemosus UBOCC-A-109155 (a cheese spoiler sometimes described as an opportunistic animal and human pathogen) [26] and Mucor endophyticus CBS 38595 (a plant endophyte [27]), were sequenced, annotated and compared to those of six publicly available Mucor and two Rhizopus (formerly identified as Mucor) isolates.

\section{Results}

\section{Genome description}

\section{Genome sequences and assembly}

The genomes of $M$. fuscus UBOCC-A-109160, M. lanceolatus UBOCC-A-109153, M. racemosus UBOCC-A-109155 and $M$. endophyticus CBS 385-95 were sequenced, assembled and annotated in the context of this study. Their genome features were compared to eight previously sequenced and annotated genomes from Mucor isolates $(n=6)$ and Rhizopus isolates formerly identified as Mucor spp. $(n=2)$ $[12,13,28]$ (Table 1). Due to the recent reassignment of the Mucor circinelloides complex members to distinct species [4], isolates identified as M. circinelloides were renamed according to their current phylogenetic placement: Mucor circinelloides CBS 277.49 was renamed into Mucor lusitanicus CBS 277.49, Mucor circinelloides CDCB5328 into Mucor velutinosus CDC-B5328 and Mucor circinelloides NBRC 6742 (synonym of Mucor ambiguus NBRC 6742) into Mucor griseocyanus NBRC 6742. For simplicity, with the exception of $M$. circinelloides and $R$. microsporus representatives (two isolates were analysed both for $M$. circinelloides and $R$. microsporus species), the different isolates investigated will, hereafter, be named by their species name.

The number of scaffolds in M. lusitanicus assembly was the lowest with 21 scaffolds. M. endophyticus was the second less fragmented assembly with 159 scaffolds. The 10 other assemblies were composed of 470 to 3888 scaffolds (Table 1).

Despite these differences in genome fragmentation, at least $95 \%$ of the 290 single copy fungal orthologous genes searched by BUSCO were found complete in all genomes. It is worth noting that respectively 52 and $87 \%$ of the searched genes were found duplicated in Rhizopus microsporus CDC-B9645 and Rhizopus microsporus CDC-B9738 genomes whereas, in the other genomes, duplicated genes only represented 17 to $26 \%$ of the searched genes. The two Rhizopus microsporus isolates also exhibited the highest genome size with $65 \mathrm{Mb}$ and $75 \mathrm{Mb}$ for CDC-B9645 and CDC-B9738 isolates, respectively, while the average size for 
Lebreton et al. BMC Genomics

(2020) 21:135

Page 3 of 21

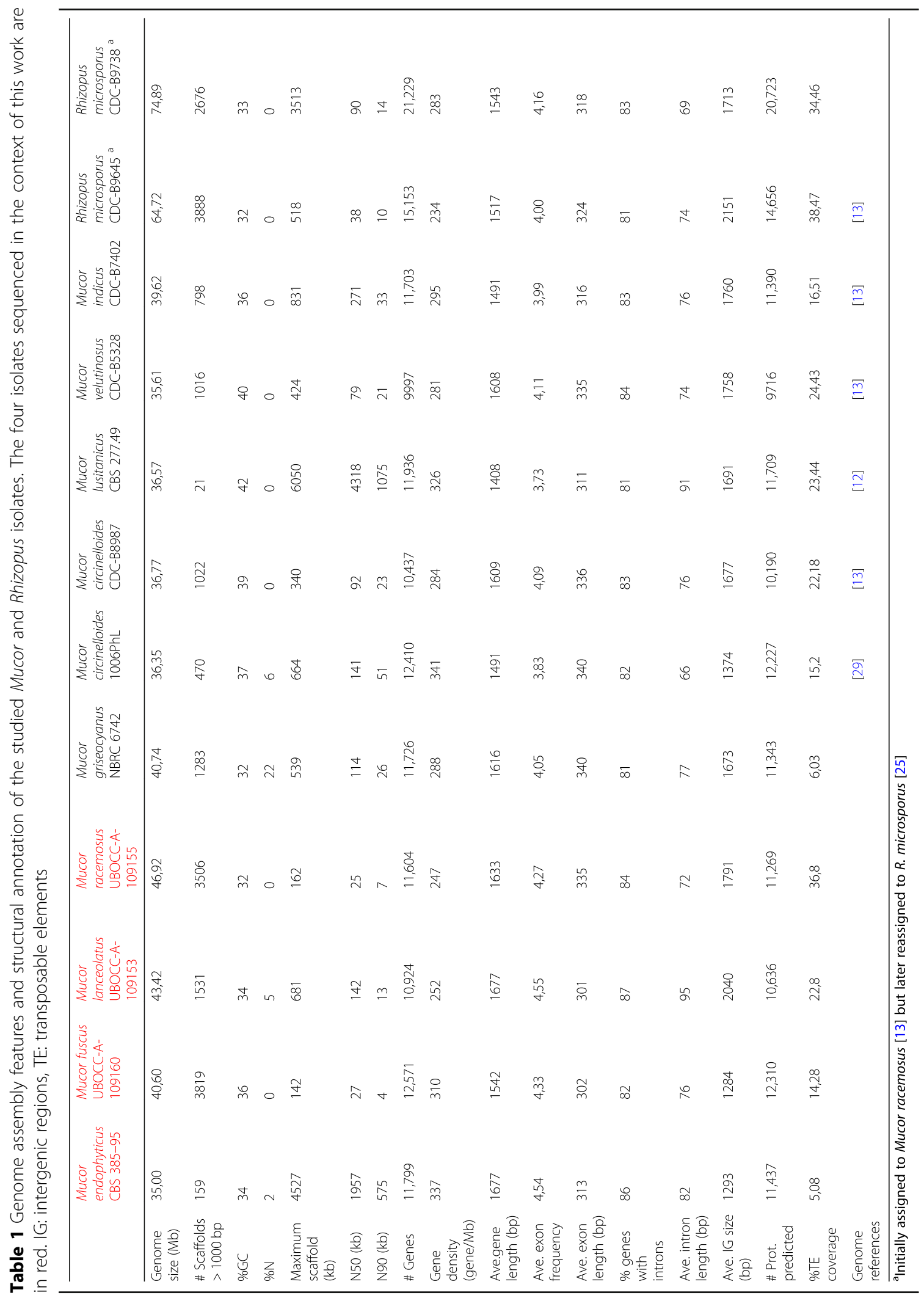


the other geomes is approximately $39 \mathrm{Mb}$. The endophytic species $M$. endophyticus, had the smallest genome size (35 $\mathrm{Mb})$ (Table 1).

\section{Genome annotation}

The number of predicted genes was in accordance with genome sizes. In Mucor species, the number of predicted genes fluctuated from 9997 to 12,571 , i.e. a gene density ranging from 247 to 341 genes/Mb, while 15,153 and 21, 229 genes were predicted for $R$. microsporus CDC-B9645 and CDC-B9738, i.e. a gene density of 234 and 283 genes/Mb, respectively (Table 1 ).

Gene characteristics were well conserved among the Mucor and Rhizopus genomes: the average gene length was $1568 \mathrm{bp}, 83 \%$ of genes had predicted introns, genes had an average frequency of 4.1 exons and average intron size was approximately $60 \mathrm{bp}$.

Noteworthy, within all genomes, the intergenic distance was variable: $25 \%$ of intergenic regions were shorter than $\sim 300 \mathrm{bp}$ whereas the largest intergenic regions exceeded $20 \mathrm{~kb}$. When repeated elements were taken into account for the analysis, regions up to $15 \mathrm{~kb}$ with neither gene nor repeated elements were still detected (Fig. 1).

\section{Genome comparisons}

\section{Phylogenomic reconstruction}

The 181,601 proteins predicted from the 10 Mucor, three Rhizopus and the Phycomyces blakesleeanus genomes were grouped in 20,588 orthogroups. Among them, 4240 orthogroups were composed of predicted proteins belonging to all genomes while 64 were composed of single copy orthologs. Among the 64-single copy orthogroups, 51 were selected to reconstruct the species tree using Maximum Likelihood and Bayesian methods, $R$. delemar and P. blakesleeanus being used as outgroups (Fig. 2a). The present study confirmed the recently described phylogenetic positions of the former $M$. circinelloides formae: M. griseocyanus, M. lusitanicus and $M$. velutinosus as distinct clades from $M$. circinelloides [4]. The placement of $M$. indicus was altered compared to the topology obtained by Whalter et al. but concurred with the topology published by Álvarez et al. $[22,24]$. Similarly, the placement of $R$. microsporus CDC-B9645 and R. microsporus CDC-B9738 was concordant with the topology of Chibucos et al. which identified these two isolates as $M$. racemosus, but clearly differentiated from the one by Gryganskyi et al. in which the two isolates were clustered with $R$. microsporus isolates (and renamed accordingly) [13, 25]. This phylogenetic position was not affected when four previously sequenced $R$. microsporus were added to the phylogenomic reconstruction (Additional file 1: Figure S1). These results clearly raise questions concerning their actual position and the genetic bases associated with these incongruences. The other studied isolates had concordant phylogenetic placements with previously published studies [13, 22, 23, 25].

From the biological point of view, M. fuscus and $M$. lanceolatus that are close in the tree, have mainly been

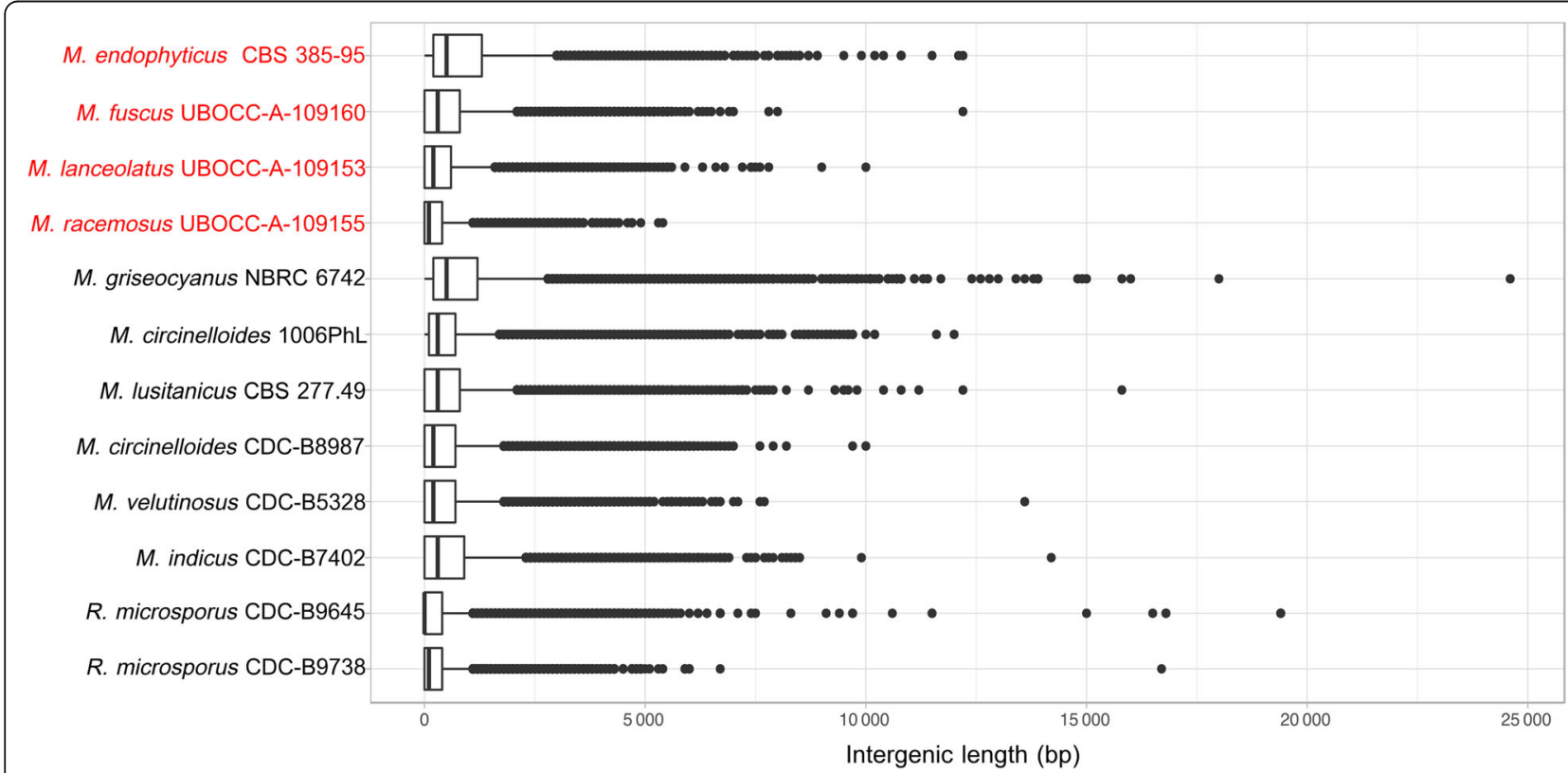

Fig. 1 Repartition of the intergenic length within the 12 studied Mucor and Rhizopus genomes. The four isolates sequenced in the context of this study are in red. The boxes represent intergenic length harbored by 25 to $75 \%$ (sorted by length) of the intergenic regions, the line within the box represent the median length, dots represent each value corresponding to the $10 \%$ longest intergenic units represented 


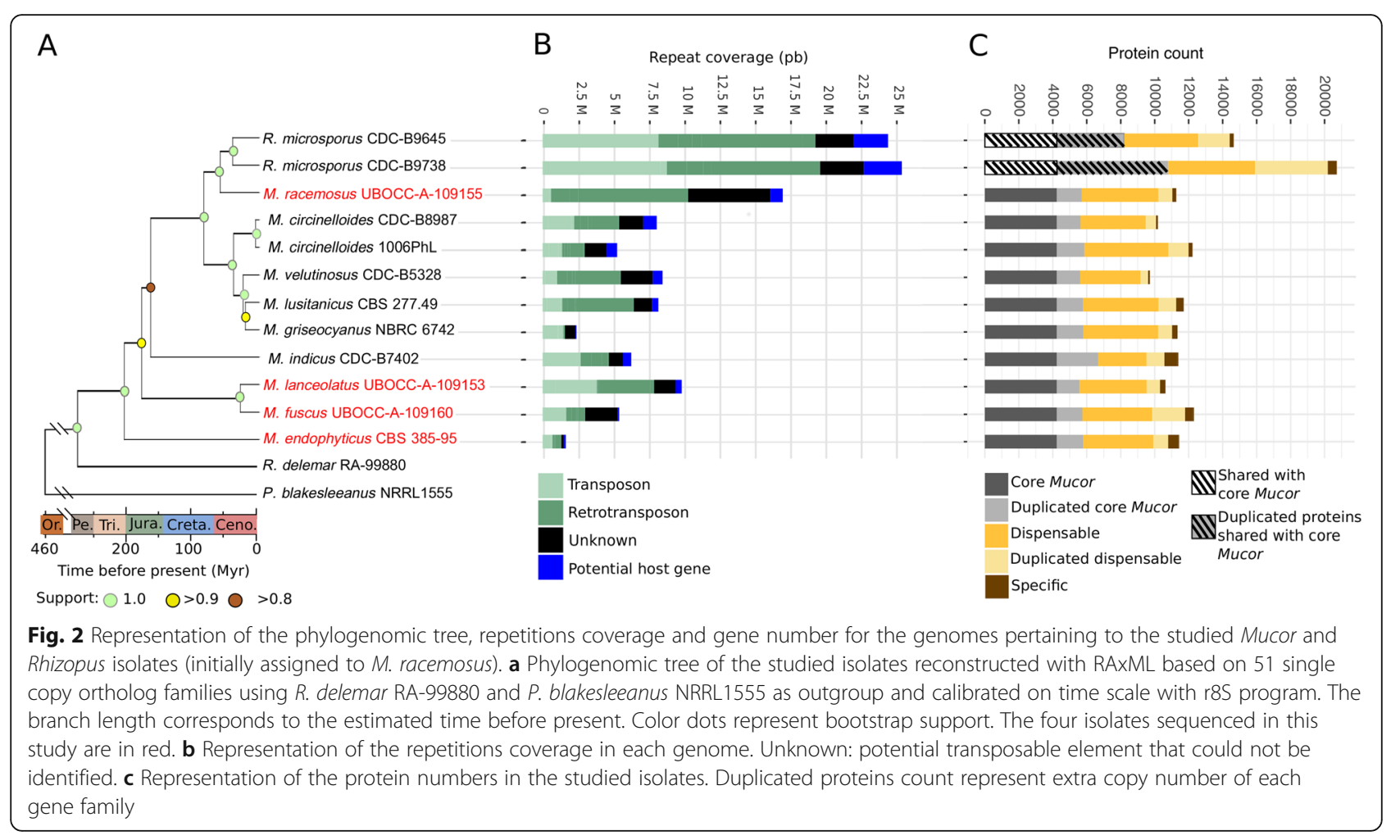

encountered in cheeses, the basal singleton M. endophyticus has only been described as a wheat leaf endophyte, whereas the other Mucor species, grouped in the same clade, are usually described as potential human pathogenic species.

\section{Transposable elements}

The studied genomes contained contrasting transposable element (TE) coverages (Fig. 2b). The plant endophyte, $M$. endophyticus, held the lowest TE coverage (5\%) whereas the ubiquitous $M$. racemosus contained the highest TE coverage (37\%). Even between close species, TE coverage and composition differed notably, e.g. between M. lanceolatus and M. fuscus or between M. griseocyanus and the other species from the $M$. circinelloides complex (M. circinelloides, M. lusitanicus and M. velutinosus). M. lanceolatus showed higher TE coverage than M. fuscus (23 and $14 \%$, respectively) for both transposons and retrotransposons but the predicted elements in M. lanceolatus were mainly non-autonomous (i.e. not including all the domains necessary for their transposition). On the contrary, almost all $M$. fuscus predicted TE were autonomous, the main represented category being terminal inverted repeat (TIR) but few retrotransposons, long interspersed nuclear elements (LINE) and long terminal repeat (LTR), were also detected (Additional file 2: Figure S2).

Among members of the $M$. circinelloides complex, three species displayed a similar pattern in terms of TE composition and, except for one of the $M$. circinelloides isolates
(1006 PhL), in terms of coverage. The fourth species, $M$. griseocyanus, displayed striking differences from the other species. Indeed, the TE coverage of M. griseocyanus was reduced by at least twofold compared to the other members (Fig. 2b). Furthermore, the main TE category was identified as belonging to the helitron order, a marginal category in the three other members of the clade.

\section{Predicted proteins repartition}

The predicted protein repertoires encoded by the 14 Mucoromycota investigated were compared with one another. This led to the identification of a set of core predicted proteins shared by all studied Mucor species and to the determination of the proteins also occurring in the studied $R$. microsporus isolates. Dispensable proteins (shared by at least two species) and species-specific proteins (only found in a single species) were also identified (Fig. 2c). For each category, duplicated proteins were identified. Despite the phylogenetic divergence between species, at least one third of the predicted proteins for each species were part of the core predicted proteome and the number of species-specific proteins was restricted.

As suggested by BUSCO results, most of $R$. microsporus predicted proteins were duplicated (Fig. 2c). This result explained the relatively low number of single copy core proteins gathered for phylogeny reconstruction despite a core Mucor proteome of approximately 6000 proteins. 


\section{Evolution of gene families across phylogeny}

When using the whole genome dataset, CAFE-, DupliPhyML- and Notung-based analyses yielded nonconcordant results (data not shown) with inconsistent placements of expansion/contraction events within the cluster encompassing $R$. microsporus CDC-B9738, $R$. microsporus CDC-B9645 and M. racemosus. This behaviour was interpreted as a side effect of a putative whole genome duplication or hybridization compatible with the observations done on the two $R$. microsporus genomes. The phylogenetic placement of these two isolates within the genus Mucor being also questioned, we decided to remove them from the CAFE analysis. CAFE identified 44 rapidly evolving gene families on the $M$. lanceolatus/M. fuscus branch (pertaining to the two species associated to cheese ripening). Among these families, two were associated to secondary metabolism, namely an acyl-CoA synthetase and a cytochrome p450 encoding gene families, both with reduced number of genes in cheese ripening species (M. fuscus and M. lanceolatus) compared to other species. A cysteine hydrolase gene family was also reduced in the two cheese-associated species. Another family (less conserved) with genes identified as encoding putative transcriptional activators of glycolytic enzyme was expanded in the latter species genomes. Other families were either unknown or similar to TE sequences.

In the M. endophyticus endophyte, at the node separating cheese-associated species from pathogenic species and at the node separating $M$. indicus from other species, 49,4 and 9 gene families were considered as rapidly evolving, respectively. However, these gene families were either of unknown function or similar to TE sequences.

\section{Genes coding for CAZymes, peptidases and small secreted proteins}

As different CAZyme and peptidase repertoires are associated to different lifestyles, comparison of the annotations of CAZyme and peptidase genes annotation of $M$. lusitanicus were publicly available in the MycoCosm database (https:// mycocosm.jgi.doe.gov/mycocosm/home). However, for the sake of the comparison, those annotations were performed again in this study following the same pipeline as the other studied genomes. This allowed to show that, for M. lusitanicus, the number of peptidase genes was found higher (351 against 304) and the number of CAZymes lower (229 against 339) in this study compared to annotation performed by the Join Genome Institute and displayed in the MycoCosm database. Taking this difference into account, the total numbers of CAZyme (155-306) (Table 2) and peptidase (332-404) encoding genes (Table 3) were found concordant with what is observed in other sequenced species of the Mucoromycota phylum as indicated in the MycoCosm protein database. In particular, the total number of CAZyme encoding genes in the Mucor genomes analysed in this study was lower than what is observed in average in Ascomycota and Basidiomycota (Additional file 3: Figure S3). Moreover, among CAZyme genes, those encoding glycosyl-transferases (GT) were found more numerous than those encoding glycoside hydrolases $(\mathrm{GH})$ which is usual in the Mucoromycota but not in Dikarya (Additional file 3: Figure S3).

Clear differences in terms of CAZyme encoding gene composition among the different genomes were detected. Among the investigated species, $M$. indicus possessed the highest content in all the CAZyme gene classes. In contrast, the number of all classes of CAZyme genes (except those encoding redox enzymes classified in auxiliary activities -AA-) was drastically reduced in $M$.

Table 2 Number of genes encoding Carbohydrate Active enZymes (CAZymes). Major CAZymes classes are shown separately, Auxiliary redox enzymes (AA), Carbohydrate-Binding Modules (CBM), Carbohydrate Esterases (CE), Glycoside Hydrolases (GH), Glycoside Transferases (GT) and Polysaccharide Lyases (PL). Enzymes substrats are indicated: Cell Wall (CW), Fungal Cell Wall (FCW) and Plant Cell Wall (PCW). The four isolates sequenced in the context of this study are in red

\begin{tabular}{|c|c|c|c|c|c|c|c|c|c|c|}
\hline Isolate & AA & CBM & CE & $\mathrm{GH}$ & GT & $P L$ & Total CAZymes & CW & FCW & PCW \\
\hline M. endophyticus CBS 385-95 & 12 & 2 & 15 & 56 & 67 & 2 & 155 & 10 & 19 & 8 \\
\hline M. fuscus UBOCC-A-109160 & 12 & 7 & 18 & 68 & 107 & 1 & 214 & 12 & 21 & 12 \\
\hline M. lanceolatus UBOCC-A-109153 & 10 & 5 & 16 & 62 & 105 & 2 & 201 & 11 & 19 & 12 \\
\hline M. racemosus UBOCC-A-109155 & 11 & 5 & 20 & 81 & 115 & 2 & 235 & 18 & 22 & 14 \\
\hline M. griseocyanus NBRC_6742 & 12 & 7 & 25 & 83 & 113 & 2 & 243 & 18 & 25 & 13 \\
\hline M. circinelloides $1006 \mathrm{PhL}$ & 15 & 7 & 23 & 83 & 121 & 2 & 252 & 18 & 24 & 14 \\
\hline M. circinelloides CDC-B8987 & 15 & 7 & 21 & 83 & 110 & 2 & 239 & 17 & 24 & 14 \\
\hline M. Iusitanicus CBS 277.49 & 11 & 5 & 23 & 75 & 112 & 2 & 229 & 16 & 22 & 12 \\
\hline M. velutinosus CDC-B5328 & 16 & 6 & 24 & 78 & 112 & 2 & 239 & 17 & 22 & 13 \\
\hline M. indicus CDC-B7402 & 25 & 11 & 34 & 96 & 136 & 3 & 306 & 20 & 28 & 15 \\
\hline
\end{tabular}


Table 3 Number of genes encoding proteolytic enzymes (peptidases) and their inhibitors (MEROPS database). The four isolates newly sequenced in the context of this study are in red

\begin{tabular}{|c|c|c|c|c|c|c|c|}
\hline \multicolumn{8}{|l|}{ Peptidases } \\
\hline Isolate & Aspartic & Cysteine & Metallo & Serine & Threonine & Total peptidases & Inhibitors \\
\hline M. endophyticus CBS 385-95 & 31 & 80 & 107 & 118 & 19 & 355 & 11 \\
\hline M. fuscus UBOCC-A-109160 & 28 & 75 & 103 & 117 & 21 & 344 & 10 \\
\hline M. lanceolatus UBOCC-A-109153 & 24 & 77 & 101 & 115 & 20 & 337 & 10 \\
\hline M. racemosus UBOCC-A-109155 & 31 & 85 & 100 & 117 & 20 & 353 & 12 \\
\hline M. griseocyanus NBRC_6742 & 32 & 84 & 101 & 110 & 20 & 347 & 10 \\
\hline M. circinelloides 1006PhL & 32 & 82 & 101 & 114 & 20 & 349 & 13 \\
\hline M. circinelloides CDC-B8987 & 30 & 78 & 94 & 109 & 21 & 332 & 11 \\
\hline M. Iusitanicus CBS 277.49 & 34 & 86 & 103 & 108 & 20 & 351 & 10 \\
\hline M. velutinosus CDC-B5328 & 29 & 85 & 103 & 109 & 21 & 347 & 13 \\
\hline M. indicus CDC-B7402 & 44 & 88 & 114 & 132 & 26 & 404 & 11 \\
\hline
\end{tabular}

endophyticus. The number of genes coding for catabolic CAZymes was also reduced in M. fuscus and M. lanceolatus. Interestingly, these reductions were noticeable for genes coding for cell wall degradation enzymes and more specifically in plant cell wall (PCW) degradation enzymes in $M$. endophyticus (Table 2). Differences among groups of species sharing a same putative lifestyle in terms of number of CAZyme families encoding genes were illustrated by the principal component analysis (PCA) of CAZymes in particular along axes 1,2 and 3 (Fig. 3). The first axis represented the opposition between the thermophilic opportunistic pathogen M. indicus and the endophyte M. endophyticus. This axis was constructed using mainly 28 CAZyme families (correlation above 0.75 ) all contracted in M. endophyticus compared to $M$. indicus, the other species presenting in almost all cases an intermediary pattern.

The second axis opposed $M$. endophyticus and $M$. indicus to all the other species. Three CAZyme families were mainly involved (correlation above 0.75 ) in this axis construction: GH8, GH20 and GT77. It is noteworthy that the GH20 $\beta$-hexosaminidase family was expanded in M. endophyticus and M. indicus, whereas the GH8 and GT77 tend to be reduced in the two latter species. The third axis represented the opposition between two species used for cheese ripening (M. fuscus and M. lanceolatus) and all the other species except $M$. indicus, the latter one presenting an intermediary pattern. Only four CAZymes families were mainly involved (correlation above 0.75 ) in this axis construction: GH9, GH37 and GT4 were contracted and GH45 expanded in M. fuscus and M. lanceolatus compared to almost all the other studied species.

Noteworthy, this analysis highlighted the GH3, GH5 (first axis) and GH9 (third axis) CAZyme families which are among the major cellulases involved in plant cell wall degradation. They were less represented in M. endophyticus and to a lesser extent in M. fuscus and M. lanceolatus (Additional file 4: Table S1).

Noteworthy, in addition to its expanded CAZyme repertoire, $M$. indicus also displayed the largest peptidase (Table 3) repertoire and, with $M$. circinelloides isolate $1006 \mathrm{PhL}$, the highest frequency of genes coding for secreted proteins and small secreted proteins (SSPs) (Fig. 4). In contrast, $M$. fuscus and $M$. lanceolatus exhibited the lowest frequencies of secreted protein and SSP encoding genes (Fig. 4).

\section{Genes involved in secondary metabolism}

As secondary metabolism genes can be associated with habitat adaptation, genes encoding PKS, NRPS, TPS and DMATS were investigated. Among genes associated with terpene biosynthesis, some corresponding to squalene cyclases, squalene synthases, bifunctional lycopene cyclases, squalene/phytoene synthases and geranylgeranyl pyrophosphate ( $g g p p)$ synthases were identified in each species. The number of genes in each category was well conserved among the different species (Table 4).

In all studied species, a single complete nrps gene (i.e. having at least one condensation domain, one carrier domain, one phosphopantetheine attachment site and 1 AMP-binding domain) was detected. Three other genes containing three of the four mandatory NRPS domains were found in $M$. indicus, both of them lacking the condensation domain, and one in M. lusitanicus, lacking the AMP-binding domain. In all species, no gene coding for DMATS were identified.

Interestingly, some gene sequences encoding putative PKS can be determined by automated annotation; however, using a manual approach, these genes actually correspond to fatty acid synthases (FAS) type I encoding genes. They were detected in the investigated genomes: three in M. indicus, one in M. fuscus and M. lanceolatus 

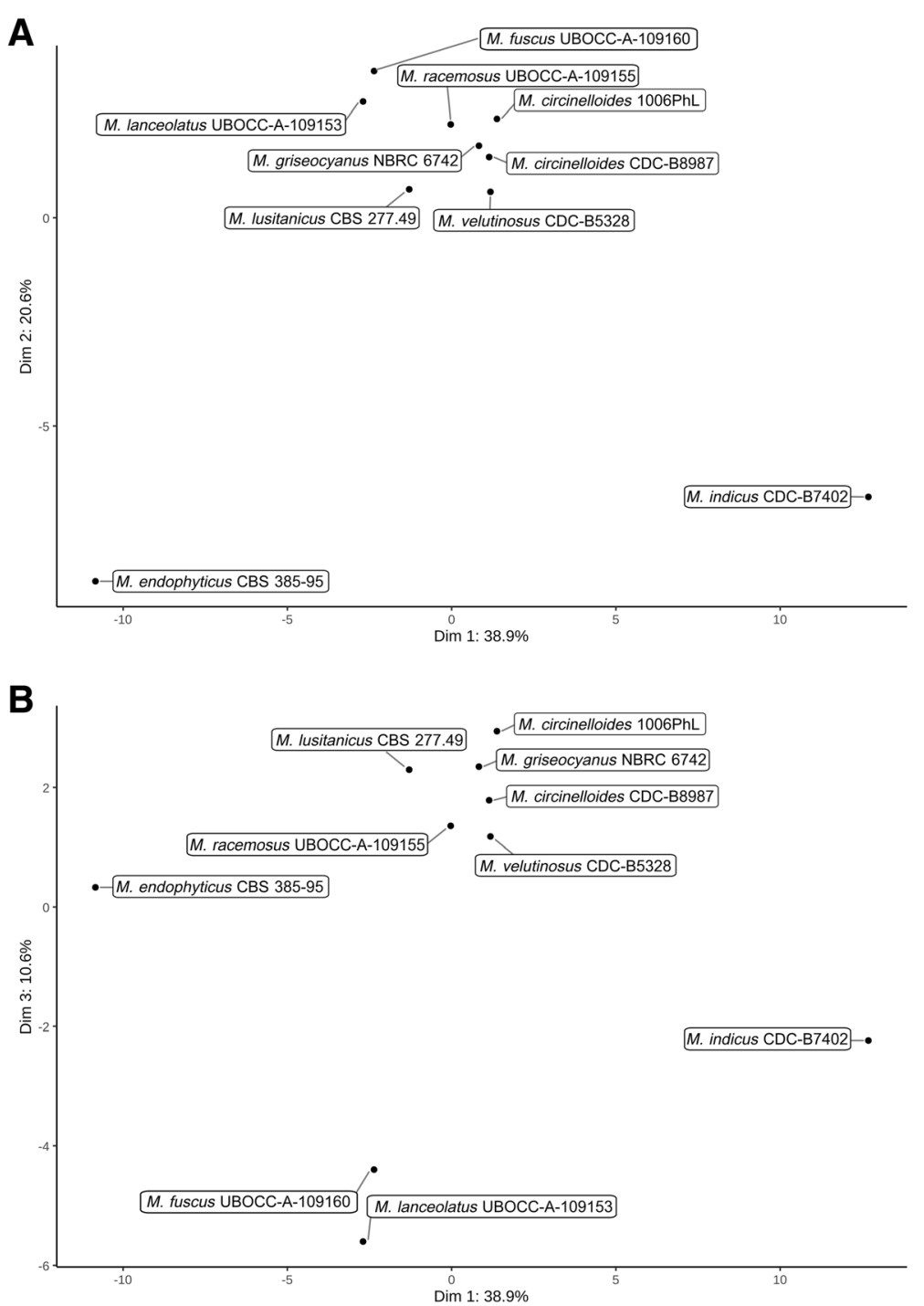

Fig. 3 Representation of Mucor isolates repartition within the PCA analysis on their CAZYmes family proteins content. a Representation of the first two dimensions. b Representation of dimensions 1 and 3

and two in the other genomes. The different domains of these genes were similar in terms of composition and organization to FAS encountered in Basidiomycota, while FAS are encoded by two genes in Ascomycota (Fig. 5). In M. indicus, M. racemosus and in M. velutinosus, one of the FAS genes held a second KS domain. Recent transcriptomic analyses indicated that these genes were not expressed on PDA medium [23]. Noteworthy, none of the potential secondary metabolism associated genes determined in the different Mucor genomes were organized in metabolic clusters.

\section{Iron uptake}

As the involvement of iron uptake in mucormycosis has been reported, the associated genes were studied [30].
Homologs of genes encoding proteins involved in the different iron uptake mechanisms identified so far in fungi [31] were found in the analysed Mucor genomes (Table 5; Fig. 6).

Regarding the siderophore-mediated iron uptake, genes playing a role in the carboxylate and hydroxamate siderophore synthesis were searched for. At least one ortholog of the $R$. delemar rfs gene, necessary for the carboxylate siderophore rhizoferrin production [33] was found in each Mucor species. Other genes that might be involved in this rhizoferrin-mediated iron uptake mechanism were identified based on their homology to the bacterial genes of the Francisella tularensis rhizoferrin operon [34]. Homologs of the FslB and FslC F. tularensis genes were detected in each Mucor genome and numerous potential Mucor 


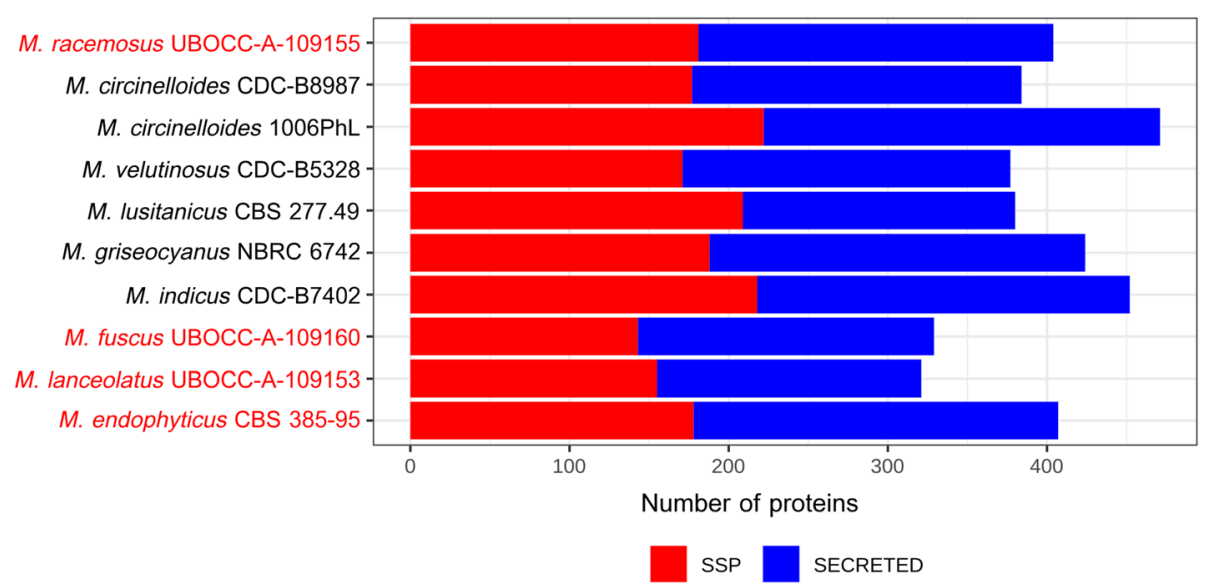

Fig. 4 Representation of the number of secreted proteins within the genomes of the studied Mucor isolates. SSP: secreted proteins containing less than 300 aa. Secreted: secreted proteins with more than 300 aa. The four isolates sequenced in the context of this study are in red

genes belonging the major facilitator family matched to FslD. However, FslA, FslE, FslF and the operon regulator Fur could not be detected in Mucor genomes. Genes involved in hydroxamate siderophore synthesis were not detected but predicted orthologous genes corresponding to the Aspergillus MirB siderophore permease (group 1) encoding gene and another gene coding for a MirB-like siderophore permease (group 2) were identified (Table 5).
Regarding the reductive iron assimilation iron uptake, homologous sequences of the gene encoding the FTR1 high-affinity permease and fet 3 ferroxidase genes were detected (fet $3 a$ was not detected in M. fuscus, M. lanceolatus and $M$. racemosus genomes). Except for the FTR1 encoding gene, no gene involved in heme uptake was identified. The FET4 low affinity iron permease encoding gene was identified in the different Mucor genomes. When focusing on the iron uptake regulation, homologs to the SreA iron uptake

Table 4 Number of genes involved in secondary metabolites found in the 10 studied Mucor isolates. The four species sequenced in this study are in red. For each gene category, maxima are highlighted in orange and minima in blue

\begin{tabular}{|c|c|c|c|c|c|c|c|c|c|c|c|}
\hline & 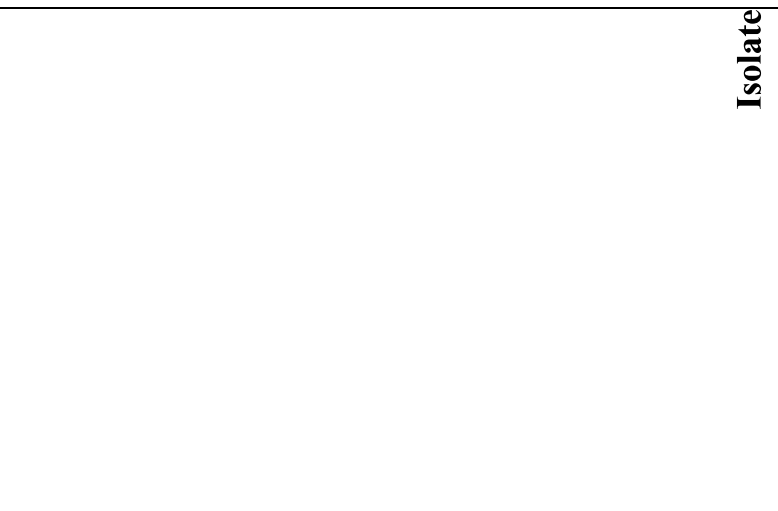 & 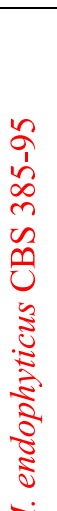 & 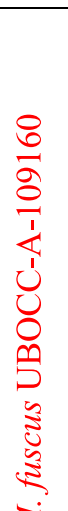 & 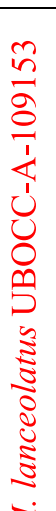 & 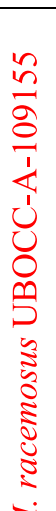 & 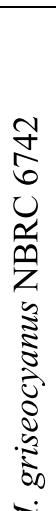 & 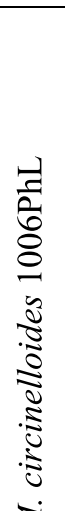 & 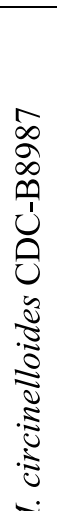 & 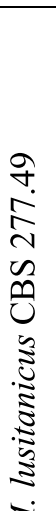 & 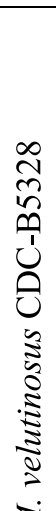 & 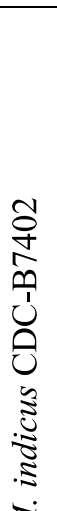 \\
\hline & & $\dot{z}$ & $\ddot{z}$ & $\dot{z}$ & $\dot{z}$ & $\dot{z}$ & $\dot{z}$ & $\dot{z}$ & $\dot{z}$ & $\dot{z}$ & $\dot{z}$ \\
\hline \multirow{4}{*}{$\begin{array}{l}\stackrel{0}{0} \\
\stackrel{0}{0} \\
\stackrel{0}{0}\end{array}$} & Squalene cyclase & 1 & 1 & 1 & 1 & 1 & 1 & 1 & 1 & 1 & 1 \\
\hline & Squalene synthase & 3 & 3 & 3 & 3 & 3 & 3 & 3 & 3 & 3 & 3 \\
\hline & Lycopene cyclase \& squalene/phytoene synthase* & 1 & 1 & 1 & 1 & 1 & 1 & 1 & 1 & 1 & 1 \\
\hline & Geranylgeranyl pyrophosphate synthase & 4 & 5 & 5 & 5 & 3 & 5 & 5 & 5 & 5 & 4 \\
\hline \multirow{2}{*}{$\begin{array}{l}\tilde{\alpha} \\
\tilde{z} \\
z\end{array}$} & NRPS & 1 & 1 & 1 & 1 & 1 & 1 & 1 & 1 & 1 & 1 \\
\hline & NRPS-like 3/4 domains & 0 & 0 & 0 & 0 & 0 & 0 & 0 & 1 & 0 & 1 \\
\hline \multirow{2}{*}{$\frac{\Omega}{2}$} & PKSI & 2 & 1 & 1 & 2 & 2 & 2 & 2 & 2 & 2 & 3 \\
\hline & 3-oxoacyl synthase II (PKS-like) & 1 & 1 & 1 & 1 & 1 & 1 & 1 & 1 & 1 & 1 \\
\hline
\end{tabular}

"These genes encode a putative bifunctional enzyme 


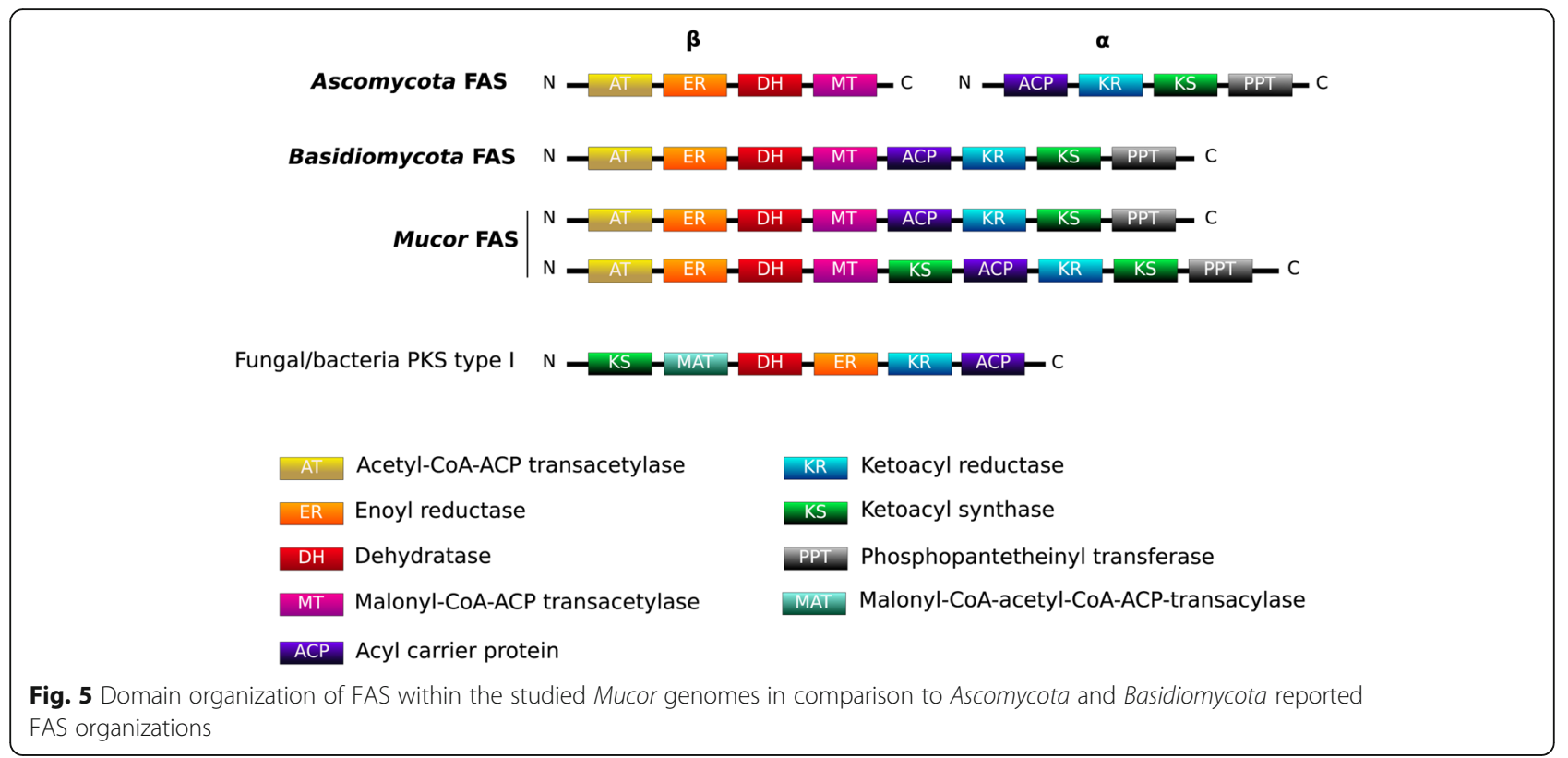

repressor gene were detected but no gene involved in activation of iron acquisition pathways such as HapX or Aft genes were identified. Two ferritin encoding genes of similar lengths were present in each studied species; in each case, the two genes shared $70 \%$ similarity and $40 \%$ identity. Interestingly, the number of genes involved in iron uptake was always higher in the genome of the opportunistic pathogen $M$. indicus than in the other genomes (Table 5). Indeed, in the $M$. indicus genome, (i) for the siderophore pathways, the $r f s$ rhizoferrin biosynthesis gene was duplicated as well as a MirB-like siderophore permease encoding gene; (ii) for the reductive iron assimilation (RIA), the fet $3 b$ and $f e t 3 c$ ferroxidase genes were duplicated; (iii) for heme degradation, a supplementary heme oxygenase gene homo$\log$ was detected and (iv) for direct $\mathrm{Fe}^{2+}$ uptake, three orthologs of the FET4 low affinity permease were identified, whereas two genes were found for the $M$. circinelloides complex and one for the other studied species. Finally, only one copy of the sreA-like gene, involved in down regulation of iron acquisition, was found in $M$. indicus whereas at least two copies were found for all other species.

On the contrary, the two cheese-associated species (M. fuscus and M. lanceolatus) exhibited a reduced number of genes involved in iron uptake within their genomes. MirB-like siderophore permease encoding gene was absent from the $M$. fuscus genome whereas one copy of $f s l B$-like siderophore permease gene was lost. M. lanceolatus lost one copy of the cell surface receptor fob gene and of the FTR1 high affinity permease, both species lacked the fet $3 a$ ferroxidase genes. The latter genes were also absent from the cheese contaminant $M$. racemosus genome.

\section{Antifungal resistance}

According to their habitat, fungi can be confronted to chemical biocide. In particular, at the hospital or in agriculture, fungicides are used and fungi can develop resistance. Based on the genome comparison we focused our attention on the antifungal resistance of the studied Mucor to triazoles.

The deduced aminoacyl sequences of the two lanosterol 14 $\alpha$-demethylase paralogues CYP51 F1 and CYP51 F5 involved in ergosterol biosynthesis were globally well conserved over the Mucor genomes with the occurrence of the F128 residue in Helix I of CYP51 F5 which has been reported to be responsible for short-chain azole resistance in Mucorales [35]. However, a two-residue substitution (AA to TS at residues 290-291) of Helix I of CYP51 F5 in M. lanceolatus was observed (Fig. 7).

According to Caramalho et al., this residue could play a role in the intrinsic resistance against triazoles. These observations raised the question of the impact of these amino acid substitutions on M. lanceolatus azole susceptibility. Growth studies on azole supplemented media clearly showed that $M$. lanceolatus was the most susceptible species to both long- (posaconazole) and shortchain (voriconazole) azoles among the tested Mucor species (Table 6) [35].

\section{Discussion}

Although benefiting from a growing interest due to their involvement in mucormycosis but also their biotechnological potential, a restricted number of Mucor genomes is available to this date, leading to scarce whole genome comparative studies $[13,15,36]$. These comparative 
Table 5 Number of genes involved in iron uptake found in the 10 studied Mucor. The four species sequenced in this study are in red. For each gene category, maxima are highlighted in orange and minima in blue. Proteins encoded by the different genes and their role in iron uptake mechanisms are presented in Fig. 6

\begin{tabular}{|c|c|c|c|c|c|c|c|c|c|c|c|c|c|}
\hline & & & 意 & 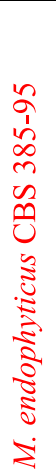 & 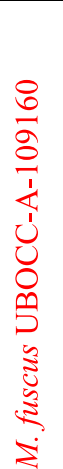 & 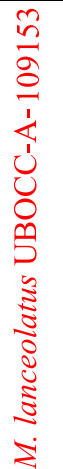 & 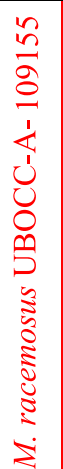 & 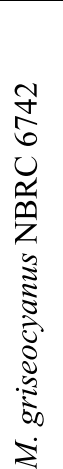 & 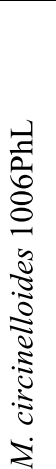 & 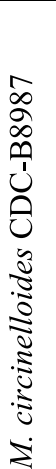 & 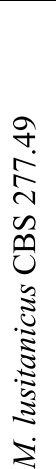 & 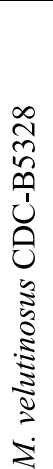 & 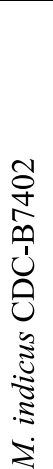 \\
\hline \multirow{13}{*}{$\begin{array}{l}\text { 节 } \\
\stackrel{0}{3}\end{array}$} & \multirow{5}{*}{$\begin{array}{l}\text { Siderophore } \\
\text { (sid) mediated } \\
\text { iron uptake }\end{array}$} & Sid-transporter: mirB-like group 1 & & 0 & 0 & 1 & 1 & 1 & 1 & 1 & 1 & 1 & 1 \\
\hline & & Sid-transporter: mirB-like group 2 & & 1 & 1 & 1 & 1 & 1 & 1 & 1 & 2 & 1 & 2 \\
\hline & & Sid-transporter: fslB & & 2 & 1 & 2 & 2 & 2 & 2 & 2 & 2 & 2 & 2 \\
\hline & & Sid-biosynthesis: rfs & & 1 & 1 & 1 & 1 & 1 & 1 & 1 & 1 & 1 & 2 \\
\hline & & Sid-biosynthesis: fslC & & 1 & 1 & 1 & 1 & 1 & 1 & 1 & 1 & 1 & 1 \\
\hline & \multirow{6}{*}{$\begin{array}{l}\text { Reductive Iron } \\
\text { Assimilation } \\
\text { (RIA) }\end{array}$} & High-affinity iron permease: FTR1 & & 2 & 1 & 1 & 1 & 2 & 2 & 2 & 2 & 2 & 2 \\
\hline & & Ferroxidase: fet3a & & 1 & 0 & 0 & 0 & 1 & 1 & 1 & 1 & 1 & 1 \\
\hline & & Ferroxidase: fet $3 b$ & & 1 & 1 & 1 & 1 & 1 & 1 & 1 & 1 & 1 & 2 \\
\hline & & Ferroxidase: fet $3 c$ & & 1 & 1 & 1 & 1 & 1 & 1 & 1 & 1 & 1 & 2 \\
\hline & & other Ferric reductase: Fre & & 5 & 3 & 3 & 4 & 4 & 4 & 4 & 3 & 4 & 4 \\
\hline & & Ferrioxamine binding: Fob & & 2 & 2 & 1 & 2 & 2 & 2 & 2 & 2 & 2 & 2 \\
\hline & \multicolumn{3}{|l|}{ Heme } & 2 & 2 & 2 & 2 & 2 & 2 & 2 & 2 & 2 & 3 \\
\hline & \multicolumn{3}{|l|}{ Low affinity } & 1 & 1 & 1 & 1 & 2 & 2 & 2 & 2 & 2 & 3 \\
\hline \multicolumn{2}{|c|}{ Iron regulation } & Transcription factor: sreA & & 2 & 2 & 2 & 2 & 2 & 2 & 2 & 2 & 2 & 1 \\
\hline \multirow{2}{*}{\multicolumn{2}{|c|}{ Iron utilization }} & Iron-binding protein frataxin: yfh1 & & 1 & 1 & 1 & 1 & 1 & 1 & 1 & 1 & 1 & 1 \\
\hline & & Vacuolar iron importer: ccc1 & & 2 & 2 & 2 & 2 & 2 & 2 & 2 & 2 & 2 & 2 \\
\hline \multirow{2}{*}{\multicolumn{2}{|c|}{ Iron storage }} & Vacuolar iron transporter: smf3 & & 3 & 3 & 3 & 3 & 3 & 3 & 3 & 3 & 2 & 3 \\
\hline & & Ferritin & & 2 & 2 & 2 & 2 & 2 & 2 & 2 & 2 & 2 & 2 \\
\hline
\end{tabular}

studies mainly focused on human/clinical environments species. Yet, only a handful of Mucor species are known to cause human infections [2]. In this context, this study expanded the range of Mucor genomes available by including genomes from species collected from non-clinical environments. In particular, $M$. endophyticus was only reported as a wheat endophyte [27] and M. lanceolatus was, so far, only collected from cheeses [26].

The determined phylogeny, based on a large set of orthologous genes (51), that integrated the four genome sequences obtained in this study is partially concordant with published phylogenies. In particular it confirmed the phylogenetic relationships amongst different members of the $M$. circinelloides complex [4] but was non-concordant with the latest published phylogeny concerning the phylogenetic position of $R$. microsporus CDC-B9738 and CDC-
B9645 isolates, as they appeared in a sister group of the $M$. circinelloides complex and closely related to $M$. racemosus. This was observed both in the present study and that of Chibucos et al. (76 analysed orthologs) while they clustered into the $R$. microsporus clade with $M$. circinelloides species as an outgroup in Gryganskyi et al. study (192 orthologues analysed) [13, 25]. Topologies may vary depending on the selected genes and on the reconstruction pipeline. The contrasted placements of the $2 R$. microsporus isolates, which harbour larger-sized genomes (Fig. 2c), among the different studies may arise from the whole/partial-genome duplication events and/or hybridization observed in their genomes [25]. As a confirmation, when considering gene families involved in secondary metabolism and iron acquisition (which were investigated in this study by comparative genomics approaches), $R$. microsporus 


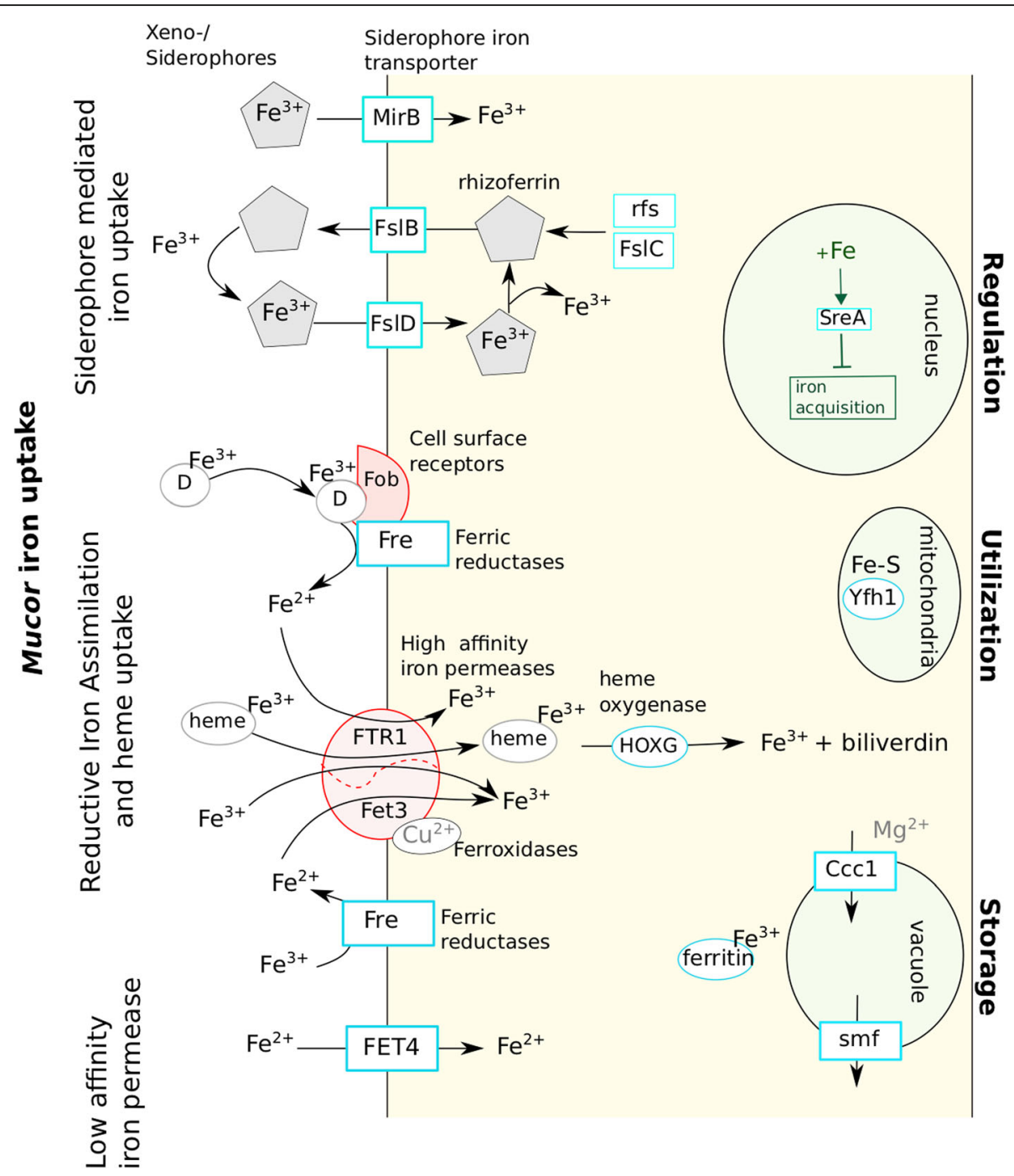

Fig. 6 Proposed mechanisms of iron uptake by Mucor spp. as well as elements used for iron regulation, utilization and storage. Elements in red were described in literature as important for Mucor pathogenicity [13, 16, 32]. D: Deferoxamine

CDC-B9738 and CDC-B9645 genes were often found duplicated. Phylogenetic reconstructions performed using the duplicates yielded incongruent topologies with either CDC-B9738 or CDC-B9645 isolates clustering with $R$. delemar clade or alternatively with $M$. racemosus clade suggesting a possible hybrid genomic content for these two isolates.

Whatever the phylogenetic placement of the studied species or their proposed habitat/lifestyle, the current study revealed that the gene features among Mucor species (gene number, size, exon length etc.) were globally conserved. However, as indicated by the lack of macroand micro-synteny (data not shown), species within this genus experienced extensive genomic rearrangements. These rearrangements can be partially explained by transposable elements (TE), which displayed high degree of diversity within the available genomes and have already been reported to have a major role in fungal genomic diversity and genome evolution [37].

The average genome size of the Mucor species analysed in this study $(39 \mathrm{Mb})$ is congruent with what is observed at the scale of the Mucoromycotina subphylum (38 Mb) and also in Ascomycota (37 Mb). The gene number (9997 to 12,571) is also in concordance with the gene numbers observed in Mucoromycotina and Ascomycota [38]. The core genome detected in this study includes approximately 6000 genes. The speciesspecific genes and the genes shared by species with similar lifestyles (data not shown) mostly encode proteins with unknown functions. They are thought to determine specific traits, such as adaptation to different environmental niches or preferential colonization of certain habitats, and determining their function would be of special interest. 


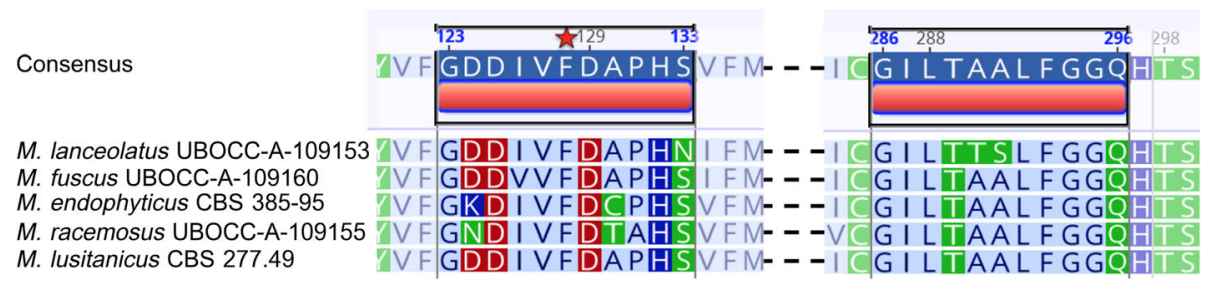

Fig. 7 Partial amino acid sequence alignment of lanosterol 14a-demethylase F5 in different Mucor isolates. The consensus sequence is represented in blue and polar amino acids appear in green. ML: M. lanceolatus; MF: M. fuscus; ME: M. endophyticus; MR: M. racemosus; MLu: M. Iusitanicus

As osmotrophic organisms, fungi depend, for gaining nutrients, on lytic enzyme secretion to externally break down surrounding resources prior to absorption of the catabolized products [39]. Depending on the lifestyle (saprotrophic, pathogenic or mutualistic) and the habitat, the way of gaining nutrients and energy may vary. In particular qualitative and quantitative differences in terms of CAZymes can be potent reporters of fungal lifestyle [38, 40-42]. In the present study, diverging CAZyme repertoires among species or species groups sharing the same ecology were identified. The genome of $M$. endophyticus CBS385-95, isolated from wheat leaves and described as an endophyte, shares similar traits with genomes of other fungal endophytes. It harbours a low number of catabolic CAZymes (CBM, GH and PL) and esterase (CE) genes [43] including genes coding for plant cell wall degrading enzymes, such as the GH5, GH3 and GH9 fungal cellulases encoding genes. This observation suggests that $M$. endophyticus, like other fungal endophytes and ectomycorrhizal fungi, is indeed adapted to intercellular growth and to the avoidance of the plant immune system [43, 44]. The two species almost only isolated from cheeses and involved in cheese ripening (M. fuscus and M. lanceolatus) also displayed, to a lesser extent than $M$. endophyticus, a reduced repertoire of carbohydrate active enzyme encoding genes. The reduction was less significant for the GT encoding genes whose roles are not directly connected to the external environment. It could be hypothesized that this reduced set of catabolic CAZymes is an imprint of specialization to a less ubiquitous lifestyle and an adaptation to the cheese environment. In contrast, the thermophilic opportunistic pathogen $M$. indicus harbours the largest set of CAZyme genes. This trait is not shared by M. circinelloides, a species that may cause mucormycosis. This could be related rather to the high capacity of $M$. indicus to degrade plant materials [45] than to an opportunistic pathogenic lifestyle. However, it is worth noting that $M$. indicus possesses a much larger protease repertoire compared to the other Mucor species including the M. circinelloides. Given that proteases [46, 47] were found clearly correlated to pathogenicity in Ascomycota opportunistic pathogens one might expect a higher pathogenicity potential of $M$. indicus over $M$. circinelloides.

Examination of secondary metabolic pathways can also shed light on fungal ecology and adaptation to a particular lifestyle [48]. In this study, we investigated more specifically genes that are essential to most of the secondary metabolite biosynthesis (PKS, NRPS, DMATS ...) but also genes involved in iron uptake which have been shown to be fundamental for fungal virulence in opportunistic pathogens $[49,50]$ and for cheese colonizing microorganisms given that cheese is a strongly ironrestricted medium [51]. The search for genes involved in secondary metabolite biosynthesis are often initiated by

Table 6 Growth diameter $(\mathrm{cm})$ of representative Mucor isolates on RPMI medium supplemented or not with different concentrations of voriconazole (VCZ) or posaconazole (PCZ)

\begin{tabular}{|c|c|c|c|c|c|c|c|c|c|c|c|c|}
\hline \multirow[b]{2}{*}{ Isolate } & \multicolumn{6}{|c|}{ VCZ concentration } & \multicolumn{6}{|c|}{ PCZ concentration } \\
\hline & $0 \mathrm{mg} / \mathrm{L}$ & 10 mg/L & 50 mg/L & 100 mg/L & $500 \mathrm{mg} / \mathrm{L}$ & $1000 \mathrm{mg} / \mathrm{L}$ & $0 \mathrm{mg} / \mathrm{L}$ & 10 mg/L & $50 \mathrm{mg} / \mathrm{L}$ & $100 \mathrm{mg} / \mathrm{L}$ & $500 \mathrm{mg} / \mathrm{L}$ & $1000 \mathrm{mg} / \mathrm{L}$ \\
\hline $\begin{array}{l}\text { M. endophyticus } \\
\text { CBS 385-95 }\end{array}$ & $\geq 5,4$ & $\geq 5,4$ & $\geq 5,4$ & $\geq 5,4$ & 0 & 0 & $\geq 5,4$ & $\geq 5,4$ & $\geq 5,4$ & $\geq 5,4$ & 0 & 0 \\
\hline $\begin{array}{l}\text { M. fuscus UBOCC- } \\
\text { A-109160 }\end{array}$ & $\geq 5,4$ & 3,2 & 0,8 & 0,2 & 0,2 & 0,2 & $\geq 5,4$ & 3 & 3 & 3 & 1,5 & 0,2 \\
\hline $\begin{array}{l}\text { M. lanceolatus } \\
\text { UBOCC-A-109153 }\end{array}$ & $\geq 5,4$ & 4,5 & 0 & 0 & 0 & 0 & $\geq 5,4$ & 0 & 0 & 0 & 0 & 0 \\
\hline $\begin{array}{l}\text { M. racemosus } \\
\text { UBOCC-A-109155 }\end{array}$ & $\geq 5,4$ & $\geq 5,4$ & $\geq 5,4$ & $\geq 5,4$ & 3,2 & 0,5 & $\geq 5,4$ & $\geq 5,4$ & $\geq 5,4$ & $\geq 5,4$ & $\geq 5,4$ & $\geq 5,4$ \\
\hline $\begin{array}{l}\text { M. Iusitanicus CBS } \\
277.49\end{array}$ & $\geq 5,4$ & $\geq 5,4$ & $\geq 5,4$ & $\geq 5,4$ & 0,3 & 0,3 & $\geq 5,4$ & $\geq 5,4$ & $\geq 5,4$ & $\geq 5,4$ & $\geq 5,4$ & $\geq 5,4$ \\
\hline
\end{tabular}


the search for PKS, NRPS or DMATS genes clustered with additional genes involved in the considered biosynthesis pathway and known as BGC (biosynthetic gene cluster). In the framework of this study, no typical BGCs involved in secondary metabolism, including a PKS, FAS, NRPS, NRPS-like gene or terpene synthesis related genes, were detected within the studied Mucor genomes. Still, secondary metabolites pathways have been characterized in Mucorales [3] and different genes involved in secondary metabolism were identified in the present and previous studies. The apparent absence or at least scarcity of BGCs within the genus Mucor (and possibly at a broader scale within the Mucoromycotina) might appear enigmatic since the genus encompasses species with contrasting lifestyles similar to what exists in Ascomycota in which BGCs are abundant. This raises the question why the apparent selective advantage conferred by BGCs to higher fungi would not apply to Mucor species. The answer to this question might lie in some ecological specificities of the Mucorales which are considered as ruderal species avoiding stress and competition [52, 53] or to structural specificities such as their coenocytic structure [54], and may shed new light regarding the BGC evolution in eukaryotes. All Mucor genomes investigated in this study included a NRPS gene which role has still to be determined as well as different genes encoding for enzymes associated with terpene biosynthesis. As noticed by Voigt et al. who analysed different Mucor genomes, no PKS genes but genes with a typical structure and domain order of Type I fatty acid synthases (FAS) were detected in the different Mucor genomes investigated in the present study [3]. These Mucor FAS have their domains allocated within a single gene as in Basidiomycota and not over two genes as in Ascomycota (Fig. 5) [55, 56]. This result supports the hypothesis of a primordial contiguous FAS gene encoding the entire FAS [55]. Most of the Mucor genomes analysed here include two putative FAS genes, but a single FAS gene was found in the cheese-related species M. lanceolatus and $M$. fuscus, and up to three genes were found in the opportunistic pathogen $M$. indicus. Whatever the number of FAS genes included in the genome, only one FAS was found expressed when the isolate was cultivated on PDA medium [23]. It could be hypothesized that the additional FAS genes have lost their functionality or display a different role since FAS gene are expected to be expressed in such conditions to participate to the fatty acid synthesis for membrane synthesis and energy storage [56]. Whether or not this additional FAS might be involved in secondary metabolisms like specialized secondary metabolism FAS [57] has to be determined.

Among the secondary metabolites, terpenes play a role in natural pigment synthesis such as the carotenoid biosynthesis [3]. Carotenoid synthesis has been described in
M. circinelloides and in particular in overproducing isolates $[3,58,59]$. Although the different species within the Mucoromycotina subphylum are expected to produce and accumulate large amount of carotenoids, differences might exist among species [60]. Terpenes play also an important role in flavour production which is an important trait for cheese-ripening fungi that could have been under human-directed selection in species used for cheese making [61]. This study indicated that the main genes involved in terpene biosynthesis were conserved among the analysed Mucor species without any important differences in terms of gene number with the exception of GGPP genes for which the number is lower in the endophytic species as well as in M. griseocyanus and in the $M$. indicus opportunistic pathogen.

Iron is an essential nutrient involved in variety of cellular processes such as respiration, oxidative stress and amino acid synthesis [62]. Iron uptake has been described as a virulence factor for pathogenic fungal isolates $[49,50]$ and of primary importance in cheese microorganisms since cheese is a highly iron-depleted medium [51]. In fungi, four different iron uptake mechanisms have been described so far: (i) siderophore mediated $\mathrm{Fe}^{3+}$ uptake, (ii) reductive iron assimilation (RIA), (iii) heme uptake and (iv) direct $\mathrm{Fe}^{2+}$ uptake [49] (Fig. 6). Homologs of genes coding for proteins participating to the four mechanisms were found in the analysed Mucor genomes. These results suggest that the different Mucor species investigated here rely on carboxylate siderophore rhizoferrin as it is the case for M. circinelloides CBS 277.49 and $R$. delemar [33]. This type of siderophore is not used by Ascomycota and Basidiomycota, and would thus be a specificity of early diverging fungi in the fungal kingdom. Noteworthy, rhizoferrin encoding gene sequences have only been described in bacterial genomes so far $[32,63]$ and coding sequences pertaining to the rhizoferrin operon in $F$. tularensis were used here to search for homologs in Mucor spp. In F. tularensis, genes involved in rhizoferrin synthesis and transport are located in an operon regulated by the Fur gene [34]. Based on these results, new candidate genes involved in rhizoferrin synthesis, import and export are proposed in the present study (Fig. 6). Although no actual evidence of Mucor ability to produce hydroxamate siderophores was detected, some of these siderophores could be used by Mucor species as xeno-siderophores as suggested by the presence of mirB-like siderophore transporter genes in some of the Mucor genomes. It is worth noting that the bacterial siderophore deferoxamine is also used by Mucor spp. as xeno-siderophores [64].

Interestingly, the three isolates sampled from cheese presented a reduced number of genes related to iron acquisition compared to the other isolates. Indeed, the genomes of these isolates lack a FTR1 gene copy as well as 
the fet $3 a$ gene. It could be hypothesized that the latter genes would have a specific role in Mucor pathogenicity since $R$. delemar mutants with FTR1 reduced gene copies or with decreased FTR1 expression had reduced virulence in a deferoxamine-treated mouse model of mucormycosis [30]. The fet3a gene appeared as the less important among the fet 3 genes regarding $M$. circinelloides pathogenicity, but inactivation of two fet 3 genes led to a reduced virulence [17] and the loss of fet $3 a$ led to an increased sensibility to the mutations on fet $3 \mathrm{~b} /$ $f e t 3 c$ in terms of fungal pathogenicity. Furthermore, one copy of the ferroxamine binding (Fob) cell surface protein gene is absent in the M. lanceolatus genome, the production of this protein being required for full virulence of $R$. delemar in a deferoxamine-treated mouse model of mucormycosis [14]. M. fuscus also lacks MirBlike and one copy of $f s l B$-like siderophore permease genes, which might reduce its potential to acquire iron. These results provide possible evidence of safety of these food-related species although the number of studied isolates is too low to definitely assert it. On the contrary, $M$. indicus, a species that is considered as the most threatening opportunistic human and animal pathogen amongst the Mucor species [7] harbours an increased set of genes involved in iron uptake which might be an asset to its opportunistic pathogenic lifestyle.

Susceptibility to antifungal drugs, and in particular to azole antifungal agents which are widely used for mucormycosis treatments as well in agriculture [35, 65], is of interest as it may vary in Mucor species according to their specific habitats, e. g. cheese isolates are probably less exposed to antifungals and antifungal resistance is unlikely to offer a selective advantage to non-pathogens. Azole drugs inhibit lanosterol $14 \alpha$-demethylase (LDM) thus blocking ergosterol biosynthesis and resulting in a build-up of toxic sterols [66]. In Mucorales, two lanosterol $14 \alpha$-demethylase paralogues CYP51 F1 and F5 coexist with a substitution in CYP51 F5 at residue 128 responsible for innate resistance against short-tailed triazoles, and a V to A substitution at residue 291 of CYP51 F5 also potentially playing a role [35]. Interestingly, we found that $M$. lanceolatus, only isolated so far from cheese, did not harbour the $\mathrm{V}$ to A substitution at residue 291 of the CYP51 F5 predicted protein but bears instead a unique two aminoacyl substitution (AA to TS) at residues 290 and 291 (in consensus sequence). Azole tests performed in this study demonstrated that these substitutions were associated with a notable higher susceptibility to both short- and long-tailed azoles.

\section{Conclusions}

In conclusion, this study expanded the range of Mucor genomes available by including genomes from species with contrasted lifestyles represented by isolates collected from non-clinical environments (more specifically, cheese and plant). In addition to yield a better overview of the Mucor pan-genome, the expanded range of genomes allowed identifying contrasting features that could contribute to habitat and niche adaptation although distinguishing divergences due respectively to evolutive adaptation or to non-ecologically based evolutionary forces may appear difficult given that the different taxa did not diverged recently. The obtained data will allow further investigating the link between genetic and biological data, especially in terms of niche or habitat adaptation.

\section{Materials and methods \\ Biological material}

The genomes of 12 representative isolates were investigated in the present study (Table 7). Four of them were sequenced in the framework of this study while the eight others were publicly available $[12,13,28]$. M. fuscus UBOCC-A-109160, M. lanceolatus UBOCC-A-109153, M. endophyticus CBS 385-95 (UBOCC-A-113049) and M. racemosus UBOCC-A-109155 used for genome sequencing were cultivated in the dark at $25^{\circ} \mathrm{C}$ on PDA solid medium (Difco Laboratories, Detroit, Michigan). Spore suspensions of each isolate were produced as previously described by Morin-Sardin et al. [7]. Concentrations were adjusted to $10^{7}$ to $10^{8}$ spores $\mathrm{mL}^{-1}$ prior to storage at $-80^{\circ} \mathrm{C}$ until use. For genomic DNA extraction, each of the studied monospore isolates was grown on PDA solid medium at $25^{\circ} \mathrm{C}$ for 7 days.

\section{Species assignment within $M$. circinelloides complex}

Species assignment of isolates pertaining to the M. circinelloides complex was performed using a Maximum Likelihood phylogenetic reconstruction based on a cyclopropane-fatty-acylphospholipidsynthase gene (cfs) sequence alignment including $c f s$ sequences available in Wagner et al. [4].

\section{Genome sequencing and assembly}

Genomic DNA from $M$. fuscus, $M$. racemosus, $M$. lanceolatus and M. endophyticus was extracted from fresh mycelium, following the genomic DNA extraction method as outlined by the 1000 Fungal Genomes Project (http://1 000.fungalgenomes.org/home/protocols/high-quality-genomic-dna-extraction/\#Fulton1995) which is based on a protocol by Spanu et al. [72]. with an optional step using Qiagen genome-tips (Qiagen). Due to the low efficiency of the CTAB method for M. lanceolatus, genomic DNA of this isolate was also extracted following the protocol developed by Cheeseman et al. with a purification by a cesium chloride gradient with DAPI [73].

Genomes were sequenced with Illumina technology (San Diego, CA) at different sequencing facilities 
Table 7 List of isolates used in this study and their reported habitat. The four isolates sequenced in the context of this study are in red

\begin{tabular}{|c|c|c|c|c|c|}
\hline Species & Isolate & Isolation source & $\begin{array}{l}\text { Reported habitat of the } \\
\text { species }\end{array}$ & $\begin{array}{l}\text { Reported habitat } \\
\text { references }\end{array}$ & $\begin{array}{l}\text { Genome reference or } \\
\text { accession }\end{array}$ \\
\hline M. endophyticus & $\begin{array}{l}\text { CBS 385-95 (UBOCC-A- } \\
113049)\end{array}$ & $\begin{array}{l}\text { Triticum aestivum, } \\
\text { leaves }\end{array}$ & Plant endophyte & [27] & This study \\
\hline M. fuscus & UBOCC-A-109160 & Cheese & Cheese & [26] & This study \\
\hline M. lanceolatus & UBOCC-A-109153 & Cheese & Cheese & [26] & This study \\
\hline M. racemosus & UBOCC-A-109155 & Cheese & $\begin{array}{l}\text { Cheese, yogurt, walnuts, } \\
\text { sausages, grassland soil, } \\
\text { decaying vegetables, } \\
\text { human }\end{array}$ & {$[24,26,67]$} & This study \\
\hline M. griseocyanus $^{\mathrm{a}}$ & NBRC 6742 & Unknown & $\begin{array}{l}\text { Vegetable, tanned sole } \\
\text { leather }\end{array}$ & [68] & BBKB00000000 \\
\hline $\begin{array}{l}\text { M. circinelloides } \mathrm{f} \text {. } \\
\text { circinelloides }\end{array}$ & $1006 \mathrm{PhL}$ & $\begin{array}{l}\text { Skin of a healthy } \\
\text { human }\end{array}$ & \multirow{4}{*}{$\begin{array}{l}\text { Cheese, sufu starter, } \\
\text { decaying vegetables, } \\
\text { human, soda, air, soil, } \\
\text { dung, sediment }\end{array}$} & \multirow[t]{4}{*}[22,24,26,69]{} & [29] \\
\hline M. circinelloides & CDC-B8987 & Human BL line & & & [13] \\
\hline M. lusitanicus ${ }^{b}$ & $\begin{array}{l}\text { CBS 277.49 (UBOCC-A- } \\
\text { 108085) }\end{array}$ & Unknown & & & [12] \\
\hline M. velutinosus ${ }^{c}$ & CDC-B5328 & Human: nasal & & & [13] \\
\hline M. indicus & $C D C-B 7402$ & Human: unknown & $\begin{array}{l}\text { Human, dung, } \\
\text { Dioscorea tuber, } \\
\text { sorghum malt }\end{array}$ & {$[24,70,71]$} & [13] \\
\hline $\begin{array}{l}\text { R. microsporus (formerly M. } \\
\text { racemosus') }\end{array}$ & $C D C-B 9645$ & Clean room floor & \multirow{2}{*}{$\begin{array}{l}\text { Human, dust, } \\
\text { sorghum malt, } \\
\text { stored cereals }\end{array}$} & \multirow[t]{2}{*}[13,24]{} & [13] \\
\hline $\begin{array}{l}\text { R. microsporus (formerly M. } \\
\text { racemosus') }\end{array}$ & CDC-B9738 & Human abdomen & & & GCA_000697275.1 \\
\hline
\end{tabular}

CBS (Centraalbureau voor Schimmelcultures, Netherlands), NBRC (Biological Ressource Center, NITE), NRRL (Agricultural Research Service Culture Collection, USA), CDC (Centers for disease Control and Prevention) and UBOCC (University of Brest Culture Collection)

a Originally M. ambiguus NBRC 6742. ' Originally M. circinelloides CBS 277.49. These isolates were reassigned according Wagner et al. [4]. Initially referenced as Mucor racemosus [13] but later assigned to Rhizopus microsporus [25]

(Additional file 5: Table S2). For each of the four species, DNA were paired end sequenced (read length $2 \times 100 \mathrm{bp}$, insert size $500 \mathrm{bp}$ ). An additional mate pair sequencing was performed for M. lanceolatus and $M$. endophyticus (read length $2 \times 100 \mathrm{bp}$, insert size 9-12 kb). Sequences were quality checked with FastQC [74]. Adaptors were removed, reads were quality trimmed (bases kept had a phred score above 25) and reads shorter than $20 \mathrm{bp}$ were dropped with Cutadapt [75]. Mate pair reads of $M$. lanceolatus were mapped with STAR [76] on a preliminary version of the assembly (by providing only $M$. lanceolatus paired end data to CLC Genomics Workbench -CLCbio, Seoul, Korea-). Mate pair reads separated by less than $500 \mathrm{bp}$ and oriented in forwardreverse were dropped. This new set of reads was used in further $M$. lanceolatus assemblies. M. lanceolatus and $M$. endophyticus genomes were assembled using Velvet [77] (option "shortMatePaired", k-mer of 67 for $M$. lanceolatus and k-mer of 85 for M. endophyticus), while $M$. racemosus and $M$. fuscus genomes were assembled with SOAPdenovo [78]. Genome assembly quality was checked with BUSCO v3 [79] using the fungal dataset and Rhizopus Augustus training.

\section{Genome annotation of the four newly sequenced genomes}

Genome assembly scaffolds were annotated using combinations of ab initio predictors, RNAseq data support and homology search. As for ab initio predictors, Genemark-ES [80], with self-training, and Augustus [81], with Rhizopus training available within the Augustus tool, were used. RNAseq transcripts were extracted and sequenced as previously described in Lebreton et al. and reconstructed using two methods [23]: (i) by mapping RNAseq reads on genome with STAR [82] and reconstructing transcripts with Cufflinks [83], and (ii) by de novo transcript reconstruction with Trinity [84] and mapping the obtained transcripts on the genomes with GMAP [85]. Predicted proteins of $M$. lusitanicus [12], $R$. delemar [9] and P. blakesleeanus [12] were searched on genomes with Exonerate [86]. Consensus gene models were generated from all predictions by EVidenceModeler [87].

The obtained gene predictions were functionally annotated as follows: transmembrane domains were predicted with TMHMM [88], peptide signal with SignalP v4 [89] and Pfam domains with HMMER [90] using the PFAMA database [91]. Sequence homologies were searched 
using tBLASTx and BLASTp [92] (with an e-value threshold inferior to $10^{-5}$, against Swissprot-Uniprot and Uniref90 databases as well as $M$. lusitanicus CBS 277-49, R. delemar RA-99880 and P. blakesleeanus NRRL1555 filtered proteins obtained from the JGI platform [93]. EC numbers were predicted using PRIAM [94] and were transferred from homology researches. GO terms were transferred from homology search. Gene names were assigned with AHRD (Automated Assignment of Human Readable Descriptions) available on Github (https://github.com/groupschoof/AHRD).

Non-coding RNA were predicted with tRNAscan-SE [95], RNAmmer [96] and Infernal [97] using the Rfam database [98]. The obtained data were integrated in an instance of the genome viewer Apollo [99] allowing experts to validate gene prediction quality and perform manual curation.

\section{Complementary annotation of the full set of genomes}

Transposable elements (TE) were annotated using the REPET pipeline [100] that includes a de novo prediction and TE classification [101]. Carbohydrate-active enzymes were searched using dbCAN2 [102] based on sequences available in the CAZy database [103] with HMMER (E-Value $<1 \mathrm{e}^{-15}$, coverage $>0.35$ ), DIAMOND [104] (E-Value $<1 \mathrm{e}^{-102}$ ) and Hotpep [105] (Frequency $>$ 6.0, Hits > 2.6). Only annotations predicted by at least two different tools were subsequently considered. Peptidases and their inhibitors available in the MEROPS database [106] were searched using BLASTp (E-Value $10^{-5}$ ).

\section{Phylogenetic reconstruction}

Predicted proteomes of the 12 studied isolates, as well as those of $R$. delemar and $P$. blakesleeanus (both latter species being considered as outgroups), were compared based on sequence similarity to identify orthologous proteins using the Orthofinder v.2.2.0 software [107] (E-value 10 ${ }^{-5}$, inflation 1.5). The 64 obtained single copy orthologs were selected to reconstruct the phylogeny of the studied species. Multiple alignment was inferred using PRANK v.170427 [108], run with default settings. Spuriously aligned regions were excluded with TrimAl v1.4.r15 [109] with a 0.2 gap threshold. Based on the alignments, 13 orthogroups were manually discarded due to low percentage of identical sites or high number of gaps among orthologs. Subsequent alignments were concatenated in a supermatrix of 23,398 sites. This matrix was used to reconstruct the species tree in one hand using Bayesian Monte Carlo Markov Chain (MCMC) samples with PhyloBayes v3.3 MCMC samplers [110] with a CAT+GTR model and 3 chains and in the other hand by Maximum Likelihood inference with RAxML PTHREADS v. 8.2.9 [111], with a partitioned $\mathrm{LG}+\mathrm{G}$ model, in which each data partition represented a single input gene family. A bootstrap analysis with 100 replicates under the same model was performed in RAxML in order to assess tree branch support. To confirm the obtained phylogenetic position of the $2 R$. microsporus isolates, an expanded species tree including 11 other sequenced Mucoromycotina (25 isolates overall) was reconstructed as follows. The 29 single copy genes families containing at least 20 isolates were independently aligned with PRANK v.170427 and trimmed with TrimAl v1.4.r15. For each gene family a gene tree was reconstructed using RAxML with the auto-detection of the best amino-acid model and a bootstrap analysis of 100 samples. The species tree was then reconstructed using the 29 gene trees with Clann v4.2.2 using a bootstrap analysis of 100 samples [112]. The obtained RAxML tree of the main species was used to estimate the divergence time between species with the Langley-Fitch method with r8s v1.8 [113] by calibrating against the assessed origins of $P$. blakesleeanus and $R$. delemar at $468 \mathrm{MY}$ [114].

\section{Evolution of genes families}

Based on OrthoFinder results and the obtained ultrametric tree, expansion and contraction of gene families were reconstructed with CAFE v4 [115]. Birth and death parameters were estimated independently using orthologous groups containing less than 75 genes per isolate. The analysis was done on all isolates except $R$. microsporus CDC-B9645 and $R$. microsporus CDC-B9738. Rapidly evolving families were predicted by CAFE using the Viterbi algorithm.

\section{Secondary metabolism related genes}

Secondary metabolism associated genes (polyketide synthase -PKS-, non-ribosomal peptide synthetase -NRPS-, terpene synthase -TPS-, dimethylallyl tryptophan synthase -DMATS-) and other genes potentially involved in adaptation to the environment (e.g. genes related to iron acquisition and to antifungal resistance) were searched in each species. Gene cluster associated with secondary metabolites were searched with antiSMASH v.4 fungal version (FungiSMASH) [116] and SMURF [117].

\section{Antifungal susceptibility}

M. lusitanicus, M. endophyticus, M. fuscus, M. lanceolatus and $M$. racemosus, as well as Byssochlamys fulva UBOCC-A-101005 (as a positive control), were grown in $5.4 \mathrm{~cm}$ Petri dishes on solid RPMI medium (Gibco BRL, Gaithersburg, MD) with $2 \%$ glucose and different concentrations of azole antifungal compounds: 0 mg. $\mathrm{l}^{-1}, 10$ mg. $\mathrm{l}^{-1}, 50 \mathrm{mg} . \mathrm{l}^{-1}, 100 \mathrm{mg} . \mathrm{l}^{-} 1,500 \mathrm{mg} . \mathrm{l}^{-1}$ and 1000 mg. $\mathrm{l}^{-1}$ of voriconazole (VCZ) (OHRE Pharam, Tours, France) or posaconazole (PCZ) (MSD France, Courbevoie, France), respectively. Each antifungal concentration was assayed in triplicates. Growth diameters were measured after 7 days. 


\section{Availability of supporting data}

Raw sequence data were deposited at the European Nucleotide Archive (ENA) (http://www.ebi.ac.uk/ena/data/ view/PRJEB30975) and genome assemblies, annotations and genome browser are available on the ABiMS platform (http://application.sb-roscoff.fr/project/mucor/) as well as on the JGI Mycocosm platform (https://genome.jgi.doe.gov/ programs/fungi/index.jsf). Noteworthy, functional annotations found on the Mycocosm platform differ from the ones exploited here since the structural annotation was functionally re-annotated by the pipelines associated with the Mycocosm platform (https://genome.jgi.doe.gov/Mucrac1, https://genome.jgi.doe.gov/Mucend1, https://genome.jgi.doe. gov/Mucfus1, https://genome.jgi.doe.gov/Muclan1). All the genome sequences compared to the genomes sequenced in the present study were found in NCBI Genome except for M. lusitanicus genome available at the Mycocosm platform.

\section{Supplementary information}

Supplementary information accompanies this paper at https://doi.org/10. 1186/s12864-019-6256-2.

Additional file 1: Figure S1. Phylogenomic tree for the genome of 25 Mucoromycotina. The tree was reconstructed using Clann based on 29 genes trees. Each tree corresponded to one of the single copy gene families included at least 20 of the 25 isolates investigated. Bootstrap supports are indicated under the branch.

Additional file 2: Figure S2. Representation of the TE coverage in each genome depending on the TE category (classification of Wicker et al.) [118]. The four species sequenced in this study are in red. DHX: Helitron transposon. DTX: TIR transposon. DXX-MITE: unknown non-autonomous transposon, MITE-like. noCat: potential transposable element that could not be identified. RIX: LINE retrotransposons. RLX: LTR retrotransposon. RXX unknown retrotransposon. RXX-LARD: unknown non-autonomous retrotransposon, LARD-like. RXX-TRIM: unknown non-autonomous retrotransposon, TRIM-like.

Additional file 3: Figure S3. Number of CAZymes in the different fungal phyla. Major CAZymes classes are shown separately, Auxiliary redox enzymes (AA), Carbohydrate-Binding Modules (CBM), Carbohydrate Esterases (CE), Glycoside Hydrolases (GH), Glycoside Transferases (GT) and Polysaccharide Lyases (PL).

Additional file 4: Table S1. Number of identified CAZyme encoding genes involved in the degradation of plant cell wall components (Cellulose active, Hemicellulose active and Pectin active). The presence of genes has been confirmed with manual annotation.

Additional file 5: Table S2. Extraction and sequencing information corresponding to the four newly sequenced Mucor isolates

\section{Abbreviations}

CAZymes: Carbohydrates Active enZymes; CYP51: 14a-demethylase paralogues; DMATS: DiMethylAllyl Tryptophan Synthase; FAS: Fatty Acid Synthase; NRPS: NonRibosomal Peptide Synthetase; PCZ: Posaconazole; PKS: Polyketide Synthase; RIA: Reductive Iron Assimilation; SSP: Small secreted protein; TPS: Terpene Synthase; VCZ: Voriconazole

\section{Acknowledgements}

The authors are thankful to Vincent Bruno, for providing the annotation of the Mucor CDC-B8987, CDC-B7402, CDC-B9645, CDC-B5328 and CDC-B9738 isolates, to Jonathan Dorival, for advices on PKS, Antoine Branca and Emmanuelle Morin for stimulating discussion, Antoine Hermet for his involvement at the early stage of the project and Stephen Mondo for the integration of Mucor genomes in the Mycocosm platform. The authors are also thankful to the two anonymous reviewers for their constructive comments. The authors thank the UBOCC strain collection (https://www.univ-brest.fr/ubocc) for providing Mucor isolates. This research was funded by the Région Bretagne (ARED program) and EQUASA, a technological platform of the Université de Bretagne Occidentale, in the framework of the MUCORSCOPE project. The M. fuscus, M. lanceolatus and M. racemosus genome sequences were obtained in the context of the French National Agency for Research (ANR)project "Food-Microbiomes".

\section{Authors' contributions}

Research idea conception: ECn, GB, LMC and JLJ. DNA Extraction: AL and RD. Antifungal assay: CLM. Analytical approach design: ECe, JLJ and LMC. Apollo instance deployment for manual annotation: LG and MM. Manual annotation: AL, JLJ, CPA, VG and LMC. Data analysis: AL, ECe, J J and LMC. Manuscript writing: $A L, J L J$ and LMC. Manuscript discussion and revision: ECn, GB and ECe. All authors read and approved the final manuscript.

\section{Funding}

This research was funded by the the Région Bretagne (ARED program) and EQUASA, a technological platform of the Université de Bretagne Occidentale, in the framework of the MUCORSCOPE project.

\section{Availability of data and materials}

Raw sequence data were deposited at the European Nucleotide Archive (ENA) (http://www.ebi.ac.uk/ena/data/view/PRJEB30975), genome assemblies and annotations are available on the ABiMS platform (http://application.sbroscoff.fr/project/mucor/).

Ethics approval and consent to participate

Not applicable.

\section{Consent for publication}

Not applicable.

\section{Competing interests}

The authors declare that they have no competing interests.

\section{Author details}

'Univ Brest, Laboratoire Universitaire de Biodiversité et Ecologie Microbienne, F-29280 Plouzané, France. ${ }^{2}$ Station Biologique de Roscoff, Plateforme ABiMS, CNRS: FR2424, Sorbonne Université (UPMC), Paris VI, Place Georges Teissier, 7429682 Roscoff Cedex, BP, France. ${ }^{3}$ CNRS, Integrative Biology of Marine Models (LBI2M), Station Biologique de Roscoff (SBR), Sorbonne Université, 29680 Roscoff, France. ${ }^{4}$ Department of Genetics and Microbiology, Faculty of Biology, University of Murcia, 30100 Murcia, Spain. ${ }^{5}$ Institute for Integrative Biology of the Cell (I2BC), CEA, CNRS, University Paris-Sud, Université Paris-Saclay, CEDEX 91198 Gif-sur-Yvette, France.

Received: 13 May 2019 Accepted: 31 October 2019

Published online: 10 February 2020

\section{References}

1. Spatafora JW, Aime MC, Grigoriev IV, Martin F, Stajich JE, Blackwell M. The fungal tree of life: From molecular systematics to genomescale phylogenies. Microbiology Spectrum. 2017;5(5). https://doi.org/10.1128/microbiolspec.FUNK0053-2016 Retrieved from https://escholarship.org/uc/item/4485m01m.

2. Morin-Sardin S, Nodet $P$, Coton $E$, Jany J-L. Mucor: a Janus-faced fungal genus with human health impact and industrial applications. Fungal Biol Rev. 2017;31(1):12-32.

3. Voigt K, Wolf T, Ochsenreiter K, Nagy G, Kaerger K, Shelest E, Papp T. In: Hoffmeister D, editor. 15 Genetic and Metabolic Aspects of Primary and Secondary Metabolism of the Zygomycetes. Cham: Springer International Publishing; 2016. p. 361-85.

4. Wagner L, Stielow B, Hoog S, Schwartze V, Kurzai O, Walther G. A new species concept for the clinically relevant Mucor circinelloides complex. Persoonia - Molecular Phylogeny and Evolution of Fungi; 2019.

5. Petrikkos G, Skiada A, Lortholary O, Roilides E, Walsh TJ, Kontoyiannis DP. Epidemiology and Clinical Manifestations of Mucormycosis. Clin Infect Dis. 2012;54(supp| 1):S23-34.

6. Pitt Jl, Hocking AD. Fungi and food spoilage. US: Springer; 2009 
7. Morin-Sardin S, Rigalma K, Coroller L, Jany JL, Coton E. Effect of temperature, $\mathrm{pH}$, and water activity on Mucor spp. growth on synthetic medium, cheese analog and cheese. Food Microbiol. 2016;56:69-79.

8. Orlowski M. Mucor dimorphism. Microbiol Rev. 1991;55(2):234-58.

9. Ma L-J, Ibrahim AS, Skory C, Grabherr MG, Burger G, Butler M, Elias M, Idnurm A, Lang BF, Sone T, et al. Genomic analysis of the basal lineage fungus Rhizopus onyzae reveals a whole-genome duplication. PLoS Genet. 2009;5(7):e1000549.

10. Khan MAK, Yang J, Hussain SA, Zhang H, Liang L, Garre V, Song Y. Construction of DGLA producing cell factory by genetic modification of Mucor circinelloides. Microb Cell Factories. 2019;18(1):64.

11. Vongsangnak W, Kingkaw A, Yang J, Song Y, Laoteng K. Dissecting metabolic behavior of lipid over-producing strain of Mucor circinelloides through genome-scale metabolic network and multi-level data integration. Gene. 2018;670:87-97.

12. Corrochano LM, Kuo A, Marcet-Houben M, Polaino S, Salamov A, VillalobosEscobedo JM, Grimwood J, Álvarez MI, Avalos J, Bauer D, et al. Expansion of signal transduction pathways in fungi by extensive genome duplication. Curr Biol. 2016;26(12):1577-84.

13. Chibucos MC, Soliman S, Gebremariam T, Lee H, Daugherty S, Orvis J, Shetty AC, Crabtree J, Hazen TH, Etienne KA, et al. An integrated genomic and transcriptomic survey of mucormycosis-causing fungi. Nat Commun. 2016;7:1-11.

14. Liu M, Lin L, Gebremariam T, Luo G, Skory CD, French SW, Chou T-F, Edwards JE Jr, Ibrahim AS. Fob1 and Fob2 proteins are virulence determinants of Rhizopus oryzae via facilitating Iron uptake from Ferrioxamine. PLoS Pathog. 2015;11(5):e1004842.

15. López-Fernández L, Sanchis M, Navarro-Rodríguez P, Nicolás FE, Silva-Franco F, Guarro J, Garre V, Navarro-Mendoza MI, Pérez-Arques C, Capilla J. Understanding Mucor circinelloides pathogenesis by comparative genomics and phenotypical studies. Virulence. 2018;9(1):707-20.

16. López-Muñoz A, Nicolás FE, García-Moreno D, Pérez-Oliva AB, Navarro-Mendoza MI, Hernández-Oñate MA, Herrera-Estrella A, Torres-Martínez S, Ruiz-Vázquez RM, Garre $V$, et al. An adult Zebrafish model reveals that Mucormycosis induces apoptosis of infected macrophages. Sci Rep. 2018;8(1):12802.

17. Navarro-Mendoza Ml, Pérez-Arques C, Murcia L, Martínez-García P, Lax C, Sanchis M, Capilla J, Nicolás FE, Garre V. Components of a new gene family of ferroxidases involved in virulence are functionally specialized in fungal dimorphism. Sci Rep. 2018;8(1):7660.

18. Patino-Medina JA, Maldonado-Herrera G, Perez-Arques C, AlejandreCastaneda V, Reyes-Mares NY, Valle-Maldonado MI, Campos-Garcia J, OrtizAlvarado R, Jacome-Galarza IE, Ramirez-Diaz MI, et al. Control of morphology and virulence by ADP-ribosylation factors (Arf) in Mucor circinelloides. Curr Genet. 2018;64(4):853-69.

19. Patiño-Medina JA, Valle-Maldonado MI, Maldonado-Herrera G, Pérez-Arques C, Jácome-Galarza IE, Díaz-Pérez C, Díaz-Pérez AL, Araiza-Cervantes CA, Villagomez-Castro JC, Campos-García J, et al. Role of Arf-like proteins (Arl1 and Arl2) of Mucor circinelloides in virulence and antifungal susceptibility. Fungal Genet Biol. 2019;129:40-51.

20. Pérez-Arques C, Navarro-Mendoza MI, Murcia L, Lax C, Martínez-García P, Heitman J, Nicolás FE, Garre V. Mucor circinelloides Thrives inside the Phagosome through an Atf-Mediated Germination Pathway. mBio. 2019; 10(1):e02765-18.

21. Trieu TA, Navarro-Mendoza Ml, Pérez-Arques C, Sanchis M, Capilla J, Navarro-Rodriguez P, Lopez-Fernandez L, Torres-Martínez S, Garre V, RuizVázquez RM, et al. RNAi-based functional genomics identifies new virulence determinants in Mucormycosis. PLoS Pathog. 2017;13(1):e1006150.

22. Álvarez E, Cano J, Stchigel AM, Sutton DA, Fothergill AW, Salas V, Rinaldi MG, Guarro J. Two new species of Mucor from clinical samples. Med Mycol. 2011;49(1):62-72.

23. Lebreton A, Meslet-Cladière L, Morin-Sardin S, Coton E, Jany J-L, Barbier G, Corre E. Comparative analysis of five Mucor species transcriptomes. Genomics. 2018;50888-7543(18):30204.

24. Walther G, Pawłowska J, Alastruey-lzquierdo A, Wrzosek M, Rodriguez-Tudela J, Dolatabadi S, Chakrabarti A, de Hoog GS. DNA barcoding in Mucorales: an inventory of biodiversity. Persoonia. 2013;30(1):11-47.

25. Gryganskyi AP, Golan J, Dolatabadi S, Mondo S, Robb S, Idnurm A, Muszewska A, Steczkiewicz K, Masonjones S, Liao H-L, et al. Phylogenetic and Phylogenomic Definition of Rhizopus Species. G3. 2018:8(6):2007-18.

26. Hermet A, Meheust D, Mounier J, Barbier G, Jany JL. Molecular systematics in the genus Mucor with special regards to species encountered in cheese. Fungal Biol. 2012;116(6):692-705.
27. Zheng R, Jiang H. Rhizomucor endophyticus sp.nov., an endophytic zygomycetes from higher plants. Mycotaxon. 1995;56:455-66.

28. Findley K, Oh J, Yang J, Conlan S, Deming C, Meyer JA, Schoenfeld D, Nomicos E, Park M, Program NCS, et al. Human skin fungal diversity. Nature. 2013;498(7454):367-70

29. Lee SC, Billmyre RB, Li A, Carson S, Sykes SM, Huh EY, Mieczkowski P, Ko DC Cuomo CA, Heitman J. Analysis of a Food-Borne Fungal Pathogen Outbreak: Virulence and Genome of a Mucor circinelloides Isolate from Yogurt. mBio. 2014:5(4)::01390-14

30. Ibrahim AS, Spellberg B, Walsh TJ, Kontoyiannis DP. Pathogenesis of Mucormycosis. Clin Infect Dis. 2012;54(suppl_1):S16-22

31. Thieken A, Winkelmann G. Rhizoferrin: a complexone type siderophore of the Mucorales and entomophthorales (Zygomycetes). FEMS Microbiol Lett. 1992;73(1-2):37-41.

32. Franken ACW, Lechner BE, Werner ER, Haas H, Lokman BC, Ram AFJ, van den Hondel CAMJJ, de Weert S, Punt PJ. Genome mining and functional genomics for siderophore production in Aspergillus Niger. Brief Funct Genomics. 2014;13(6):482-92.

33. Carroll CS, Grieve CL, Murugathasan I, Bennet AJ, Czekster CM, Liu H, Naismith J, Moore MM. The rhizoferrin biosynthetic gene in the fungal pathogen Rhizopus delemar is a novel member of the NIS gene family. Int Biochem Cell Biol. 2017;89:136-46.

34. Ramakrishnan G. Iron and virulence in Francisella tularensis. Front Cell Infect Microbiol. 2017;7:107.

35. Caramalho R, Tyndall JDA, Monk BC, Larentis T, Lass-Flörl C, Lackner M. Intrinsic short-tailed azole resistance in mucormycetes is due to an evolutionary conserved aminoacid substitution of the lanosterol 14ademethylase. Sci Rep. 2017;7(1):-15898.

36. Tang $X$, Chen $H$, Chen YQ, Chen W, Garre V, Song Y, Ratledge C. Comparison of biochemical activities between high and low lipidproducing strains of Mucor circinelloides: an explanation for the high Oleaginicity of strain WJ11. PLoS One. 2015;10(6):e0128396.

37. Castanera R, López-Varas L, Borgognone A, LaButti K, Lapidus A, Schmutz J, Grimwood J, Pérez G, Pisabarro AG, Grigoriev IV, et al. Transposable elements versus the fungal genome: impact on whole-genome architecture and transcriptional profiles. PLoS Genet. 2016;12(6):e1006108.

38. Zhao Z, Liu H, Wang C, Xu J-R. Comparative analysis of fungal genomes reveals different plant cell wall degrading capacity in fungi. BMC Genomics. 2013;14(1):274.

39. Heitman J, Howlett BJ, Crous PW, Stukenbrock EH, James TY, Gow NAR. The fungal kingdom: American Society of Microbiology; 2017.

40. Pain A, Hertz-Fowler C. Genomic adaptation: a fungal perspective. Nat Rev Microbiol. 2008:6:572.

41. Plett JM, Martin F. Blurred boundaries: lifestyle lessons from ectomycorrhizal fungal genomes. Trends Genet. 2011;27(1):14-22.

42. Knapp DG, Németh JB, Barry K, Hainaut M, Henrissat B, Johnson J, Kuo A, Lim JHP, Lipzen A, Nolan M, et al. Comparative genomics provides insights into the lifestyle and reveals functional heterogeneity of dark septate endophytic fungi. Sci Rep. 2018;8(1):6321.

43. Gazis R, Kuo A, Riley R, LaButti K, Lipzen A, Lin J, Amirebrahimi M, Hesse CN, Spatafora JW, Henrissat B, et al. The genome of Xylona heveae provides a window into fungal endophytism. Fungal Biol. 2016;120(1):26-42.

44. Kohler A, Kuo A, Nagy LG, Morin E, Barry KW, Buscot F, Canbäck B, Choi C, Cichocki N, Clum A, et al. Convergent losses of decay mechanisms and rapid turnover of symbiosis genes in mycorrhizal mutualists. Nat Genet. 2015:47:410.

45. Karimi K, Zamani A. Mucor indicus: biology and industrial application perspectives: a review. Biotechnol Adv. 2013;31(4):466-81.

46. Kogan TV, Jadoun J, Mittelman L, Hirschberg K, Osherov N. Involvement of secreted Aspergillus fumigatus proteases in disruption of the actin Fiber cytoskeleton and loss of focal adhesion sites in infected A549 lung Pneumocytes. J Infect Dis. 2004;189(11):1965-73.

47. Shankar J, Tiwari S, Shishodia SK, Gangwar M, Hoda S, Thakur R, Vijayaraghavan P. Molecular insights into development and virulence determinants of Aspergilli: a proteomic perspective. Front Cell Infect Microbiol. 2018;8:180.

48. Rokas A, Wisecaver JH, Lind AL. The birth, evolution and death of metabolic gene clusters in fungi. Nat Rev Microbiol. 2018;16:731-44.

49. Bairwa G, Hee Jung W, Kronstad JW. Iron acquisition in fungal pathogens of humans. Metallomics. 2017;9(3):215-27.

50. Haas H. Iron - a key Nexus in the virulence of Aspergillus fumigatus. Front Microbiol. 2012;3:28 
51. Monnet C, Loux V, Gibrat J-F, Spinnler E, Barbe V, Vacherie B, Gavory F, Gourbeyre E, Siguier P, Chandler MJPO. The Arthrobacter arilaitensis Re117 genome sequence reveals its genetic adaptation to the surface of cheese. PLoS One. 2010;5(11):e15489.

52. Andrews JH. Fungal life-history strategies. Fungal Commun. 1992;2:119-45.

53. Cooke RC, Rayner AD. Ecology of saprotrophic fungi: Longman; 1984.

54. Howard DH. Pathogenic fungi in humans and animals. New York: Marcel Dekker; 2003

55. Herbst DA, Townsend CA, Maier T. The architectures of iterative type I PKS and FAS. Nat Prod Rep. 2018;35:1046-69.

56. Maier T, Leibundgut M, Boehringer D, Ban N. Structure and function of eukaryotic fatty acid synthases. Q Rev Biophys. 2010;43(3):373-422.

57. Hitchman TS, Schmidt EW, Trail F, Rarick MD, Linz JE, Townsend CA. Hexanoate synthase, a specialized type I fatty acid synthase in Aflatoxin B1 biosynthesis. Bioorg Chem. 2001;29(5):293-307.

58. Csernetics Á, Nagy G, Iturriaga EA, Szekeres A, Eslava AP, Vágvölgyi C, Papp T. Biology: Expression of three isoprenoid biosynthesis genes and their effects on the carotenoid production of the zygomycete Mucor circinelloides. Fungal Genet Biol. 2011;48(7):696-703.

59. Navarro E, Sandmann G, Torres-Martínez S. Mutants of the carotenoid biosynthetic pathway of Mucor circinelloides. Exp Mycol. 1995;19(3):186-90.

60. Zhang Y, Navarro E, Cánovas-Márquez JT, Almagro L, Chen H, Chen YQ, Zhang H, Torres-Martínez S, Chen W, Garre V. A new regulatory mechanism controlling carotenogenesis in the fungus Mucor circinelloides as a target to generate $\beta$-carotene over-producing strains by genetic engineering. Microb Cell Factories. 2016;15:99.

61. Ropars J, Lo Y-C, Dumas E, Snirc A, Begerow D, Rollnik T, Lacoste S, Dupont J, Giraud T, López-Villavicencio M. Fertility depression among cheesemaking Penicillium roqueforti strains suggests degeneration during domestication. Evolution. 2016;70(9):2099-109.

62. Winkelmann G. Specificity of iron transport in bacteria and fungi. In: Handbook of Microbial Iron Chelates. Boca Raton: CRC Press; 1991. p. 73-114.

63. Khan A. Synthesis, nature and utility of universal iron chelator siderophore: a review. Microbiol Res. 2017;212:103-11.

64. Szebesczyk A, Olshvang E, Shanzer A, Carver PL, Gumienna-Kontecka E. Harnessing the power of fungal siderophores for the imaging and treatment of human diseases. Coord Chem Rev. 2016;327-328: 84-109.

65. Graninger W, Diab-Elschahawi M, Presterl E. Antifungal Agents. In: Presterl E, editor. Clinically Relevant Mycoses: A Practical Approach. Cham: Springer International Publishing; 2019. p. 31-42.

66. Woolley DW. Some new aspects of the relationship of chemical structure to biological activity. Science. 1944;100(2609):579-83.

67. Ozturkoglu-Budak S, Wiebenga A, Bron PA, de Vries RP. Protease and lipase activities of fungal and bacterial strains derived from an artisanal raw ewe's milk cheese. Int J Food Microbiol. 2016;237:17-27.

68. Falkiewicz-Dulík M. 6.8 - Leather and leather products. In: Falkiewicz-Dulik M, Janda K, Wypych G, editors. Handbook of Material Biodegradation, Biodeterioration, and Biostablization. 2nd ed. Toronto: ChemTec Publishing; 2015. p. 133-256.

69. Joichi Y, Chijimatsu I, Yarita K, Kamei K, Miki M, Onodera M, Harada M, Yokozaki M, Kobayashi M, Ohge H. Detection of Mucor velutinosus in a blood culture after autologous peripheral blood stem cell transplantation : a pediatric case report. Med Mycol J. 2014;55(2):E43-8

70. Singh P, Paul S, Shivaprakash MR, Chakrabarti A, Ghosh AK. Stress response in medically important Mucorales. Mycoses. 2016;59(10):628-35.

71. Taj-Aldeen SJ, Almaslamani M, Theelen B, Boekhout T. Phylogenetic analysis reveals two genotypes of the emerging fungus Mucor indicus, an opportunistic human pathogen in immunocompromised patients. Emerg Microbes Infect. 2017:6(7):e63.

72. Fulton TM, Chunwongse J, Tanksley SD. Microprep protocol for extraction of DNA from tomato and other herbaceous plants. Plant Mol Biol Report. 1995;13(3):207-9.

73. Cheeseman K, Ropars J, Renault P, Dupont J, Gouzy J, Branca A, Abraham AL, Ceppi M, Conseiller E, Debuchy R, et al. Multiple recent horizontal transfers of a large genomic region in cheese making fungi. Nat Commun 2014;5:2876.

74. Andrews S. FASTQC: A quality control tool for high throughput sequence data; 2010.

75. Martin M. Cutadapt removes adapter sequences from high-throughput sequencing reads. EMBnet J. 2011;17(1):10-2.
76. Dobin A, Davis CA, Schlesinger F, Drenkow J, Zaleski C, Jha S, Batut P, Chaisson M, Gingeras TR. STAR: ultrafast universal RNA-seq aligner. Bioinformatics. 2013;29(1):15-21.

77. Zerbino DR, Birney E. Velvet: Algorithms for de novo short read assembly using de Bruijn graphs. Genome Res. 2008;18(5):821-9.

78. Luo R, Liu B, Xie Y, Li Z, Huang W, Yuan J, He G, Chen Y, Pan Q, Liu Y, et al. SOAPdenovo2: an empirically improved memory-efficient short-read de novo assembler. GigaScience. 2012;1:18.

79. Waterhouse RM, Seppey M, Simão FA, Manni M, loannidis P, Klioutchnikov G, Kriventseva EV, Zdobnov EM. BUSCO applications from quality assessments to gene prediction and Phylogenomics. Mol Biol Evol. 2018; 35(3):543-8.

80. Ter-Hovhannisyan V, Lomsadze A, Chernoff YO, Borodovsky M. Gene prediction in novel fungal genomes using an ab initio algorithm with unsupervised training. Genome Res. 2008;18(12):1979-90.

81. Stanke M, Schöffmann O, Morgenstern B, Waack S. Gene prediction in eukaryotes with a generalized hidden Markov model that uses hints from external sources. BMC Bioinformatics. 2006;7(1):62.

82. Dobin A, Gingeras TR. Mapping RNA-seq reads with STAR. Curr Protoc Bioinformatics. 2015;51:11.14.11-9.

83. Trapnell C, Williams BA, Pertea G, Mortazavi A, Kwan G, van Baren MJ, Salzberg SL, Wold BJ, Pachter L. Transcript assembly and abundance estimation from RNA-Seq reveals thousands of new transcripts and switching among isoforms. Nat Biotechnol. 2010;28(5):511-5.

84. Grabherr MG, Haas BJ, Yassour M, Levin JZ, Thompson DA, Amit I, Adiconis X, Fan L, Raychowdhury R, Zeng Q, et al. Trinity: reconstructing a full-length transcriptome without a genome from RNA-Seq data. Nat Biotechnol. 2011; 29(7):644-52.

85. Wu TD, Watanabe CK. GMAP: a genomic mapping and alignment program for mRNA and EST sequences. Bioinformatics. 2005;21(9):1859-75.

86. Slater GSC, Birney E. Automated generation of heuristics for biological sequence comparison. BMC Bioinformatics. 2005;6(1):31.

87. Haas BJ, Salzberg SL, Zhu W, Pertea M, Allen JE, Orvis J, White O, Buell CR, Wortman JR. Automated eukaryotic gene structure annotation using EVidenceModeler and the Program to assemble spliced alignments. Genome Biol. 2008:9(1):R7.

88. Krogh A, Larsson B, von Heijne G, Sonnhammer E. Predicting transmembrane protein topology with a hidden Markov model: application to complete genomes. J Mol Biol. 2001;305(3):567-80.

89. Petersen TN, Brunak S, von Heijne G, Nielsen H. SignalP 4.0: discriminating signal peptides from transmembrane regions. Nat Methods. 2011;8:785.

90. Eddy SR. Accelerated profile HMM searches. PLoS Comput Biol. 2011;7(10):e1002195.

91. Finn RD, Coggill P, Eberhardt RY, Eddy SR, Mistry J, Mitchell AL, Potter SC, Punta M, Qureshi M, Sangrador-Vegas A, et al. The Pfam protein families database: towards a more sustainable future. Nucleic Acids Res. 2016:44(D1):D279-85.

92. Altschul SF, Gish W, Miller W, Myers EW, Lipman DJ. Basic local alignment search tool. J Mol Biol. 1990;215(3):403-10.

93. Grigoriev IV, Nikitin R, Haridas S, Kuo A, Ohm R, Otillar R, Riley R, Salamov A, Zhao X, Korzeniewski F, et al. MycoCosm portal: gearing up for 1000 fungal genomes. Nucleic Acids Res. 2014;42(D1):D699-704.

94. Claudel-Renard C, Chevalet C, Faraut T, Kahn D. Enzyme-specific profiles for genome annotation: PRIAM. Nucleic Acids Res. 2003;31(22):6633-9.

95. Lowe TM, Chan PP. tRNAscan-SE On-line: integrating search and context for analysis of transfer RNA genes. Nucleic Acids Res. 2016;44(Web Server issue):W54-7.

96. Lagesen K, Hallin P, Rodland EA, Staerfeldt HH, Rognes T, Ussery DW. RNAmmer: consistent and rapid annotation of ribosomal RNA genes. Nucleic Acids Res. 2007;35(9):3100-8.

97. Nawrocki EP, Eddy SR. Infernal 1.1: 100-fold faster RNA homology searches. Bioinformatics. 2013;29(22):2933-5.

98. Nawrocki EP, Burge SW, Bateman A, Daub J, Eberhardt RY, Eddy SR, Floden EW, Gardner PP, Jones TA, Tate J, et al. Rfam 12.0: updates to the RNA families database. Nucleic Acids Res. 2015;43(Database issue):D130-7.

99. Dunn N A, Unni D, Diesh C, Munoz-Torres M, Harris N L, Yao E, Rasche H, Holmes I H, Elsik C G, Lewis S E: Apollo: democratizing genome annotation. PLoS Comput Biol. 2019;15(2):e1006790.

100. Flutre T, Duprat E, Feuillet C, Quesneville H. Considering transposable element diversification in De novo annotation approaches. PLoS One. 2011;6(1):e16526.

101. Hoede C, Arnoux S, Moisset M, Chaumier T, Inizan O, Jamilloux V, Quesneville H. PASTEC: an automatic transposable element classification tool. PLoS One. 2014;9(5):e91929. 
102. Zhang H, Yohe T, Huang L, Entwistle S, Wu P, Yang Z, Busk PK, Xu Y, Yin Y. dbCAN2: a meta server for automated carbohydrate-active enzyme annotation. Nucleic Acids Res. 2018;46(W1):W95-W101.

103. Lombard V, Golaconda Ramulu H, Drula E, Coutinho PM, Henrissat B. The carbohydrate-active enzymes database (CAZy) in 2013. Nucleic Acids Res. 2014;42(Database issue):D490-5.

104. Buchfink B, Xie C, Huson DH. Fast and sensitive protein alignment using DIAMOND. Nat Methods. 2014;12:59.

105. Busk PK, Pilgaard B, Lezyk MJ, Meyer AS, Lange L. Homology to peptide pattern for annotation of carbohydrate-active enzymes and prediction of function. BMC Bioinformatics. 2017;18(1):214

106. Rawlings ND, Barrett AJ, Finn R. Twenty years of the MEROPS database of proteolytic enzymes, their substrates and inhibitors. Nucleic Acids Res. 2016; 44(D1):D343-50.

107. Emms DM, Kelly S. OrthoFinder: solving fundamental biases in whole genome comparisons dramatically improves orthogroup inference accuracy. Genome Biol. 2015;16(1):157.

108. Löytynoja A. Phylogeny-aware alignment with PRANK. Methods Mol Biol. 2014;1079:155-70

109. Capella-Gutiérrez S, Silla-Martínez JM, Gabaldón T. trimAl: a tool for automated alignment trimming in large-scale phylogenetic analyses. Bioinformatics. 2009:25(15):1972-3.

110. Lartillot N, Rodrigue N, Stubbs D, Richer J. PhyloBayes MPI: phylogenetic reconstruction with infinite mixtures of profiles in a parallel environment. Syst Biol. 2013;62(4):611-5.

111. Stamatakis A. RAxML version 8: a tool for phylogenetic analysis and postanalysis of large phylogenies. Bioinformatics. 2014;30(9):1312-3.

112. Creevey CJ, Mclnerney JO. Clann: investigating phylogenetic information through supertree analyses. Bioinformatics. 2004;21(3):390-2.

113. Sanderson MJ. r8s: inferring absolute rates of molecular evolution and divergence times in the absence of a molecular clock. Bioinformatics. 2003; 19(2):301-2.

114. Zhou P, Zhang G, Chen S, Jiang Z, Tang Y, Henrissat B, Yan Q, Yang S, Chen $C-F$, Zhang B, et al. Genome sequence and transcriptome analyses of the thermophilic zygomycete fungus Rhizomucor miehei. BMC Genomics. 2014; 15(1):294

115. Han MV, Thomas GWC, Lugo-Martinez J, Hahn MW. Estimating gene gain and loss rates in the presence of error in genome assembly and annotation using CAFE 3. Mol Biol Evol. 2013;30(8):1987-97.

116. Blin K, Wolf T, Chevrette MG, Lu X, Schwalen CJ, Kautsar SA, Suarez Duran HG, de Los Santos ELC, Kim HU, Nave M, et al. antiSMASH 4.0-improvements in chemistry prediction and gene cluster boundary identification. Nucleic Acids Res. 2017;45(W1):W36-41.

117. Khaldi N, Seifuddin FT, Turner G, Haft D, Nierman WC, Wolfe KH, Fedorova ND. SMURF: genomic mapping of fungal secondary metabolite clusters. Fungal Genet Biol. 2010;47(9):736-41.

118. Wicker T, Sabot F, Hua-Van A, Bennetzen JL, Capy P, Chalhoub B, Flavell A, Leroy $\mathrm{P}$, Morgante $\mathrm{M}$, Panaud $\mathrm{O}$, et al. A unified classification system for eukaryotic transposable elements. Nat Rev Genet. 2007;8(12):973-82.

\section{Publisher's Note}

Springer Nature remains neutral with regard to jurisdictional claims in published maps and institutional affiliations.

Ready to submit your research? Choose BMC and benefit from:

- fast, convenient online submission

- thorough peer review by experienced researchers in your field

- rapid publication on acceptance

- support for research data, including large and complex data types

- gold Open Access which fosters wider collaboration and increased citations

- maximum visibility for your research: over $100 \mathrm{M}$ website views per year

At $\mathrm{BMC}$, research is always in progress.

Learn more biomedcentral.com/submissions 